\title{
A PENAPARDA (A FONSAGRADA, LUGO - SANTALLA, ASTURIAS): INTERVENCIÓN ARQUEOLÓGICA EN UN RECINTO CAMPAMENTAL ROMANO EN EL OCCIDENTE DE LA CORDILLERA CANTÁBRICA
}

\author{
José Manuel Costa-García \\ Universidad de Santiago de Compostela \\ ORCID iD: https://orcid.org/0000-0002-0819-1361 \\ ANDRÉs MENÉNDEZ Blanco \\ Arqueólogo, investigador independiente \\ ORCID iD: https://orcid.org/0000-0002-7190-5240 \\ JoÃo FonTE \\ Instituto de Ciencias del Patrimonio (CSIC) y University of Exeter \\ ORCID iD: https://orcid.org/0000-0003-0367-0598 \\ Francisco AlONSO Toucido \\ Universidad de Santiago de Compostela \\ ORCID iD: https://orcid.org/0000-0003-2554-5448
}

\begin{abstract}
Copyright: (C 2020 CSIC. La edición electrónica de esta revista se distribuye bajo los términos de una licencia de uso y distribución Creative Commons Reconocimiento 4.0 Internacional (CC BY 4.0).

Cómo citar/Citation: José Manuel CostA-GARCíA, et al., "A Penaparda (A Fonsagrada, Lugo Santalla, Asturias): intervención arqueológica en un recinto campamental romano en el Occidente de la Cordillera Cantábrica”, Cuadernos de Estudios Gallegos, 67, núm. 133 (2020), págs. 45-74, https://doi.org/10.3989/ceg.2020.133.02
\end{abstract}




\title{
A PENAPARDA (A FONSAGRADA, LUGO - SANTALLA, ASTURIAS): \\ INTERVENCIÓN ARQUEOLÓGICA EN UN RECINTO CAMPAMENTAL ROMANO \\ EN EL OCCIDENTE DE LA CORDILLERA CANTÁBRICA
}

\section{RESUMEN}

En este trabajo se presentan los resultados de la intervención arqueológica realizada en 2017 en el yacimiento de A Penaparda, un recinto campamental en forma de naipe de aproximadamente 10 ha situado a caballo entre los municipios de A Fonsagrada (Lugo) y Santalla (Asturias). Partiendo de una prospección arqueológica previa de las sierras de Ouroso-Penouta con recurso a teledetección, esta campaña contempló el reconocimiento integral de las estructuras arqueológicas tanto en superficie como por teledetección, la prospección artefactual y por metalodetección de un sector del yacimiento y la apertura de un sondeo exploratorio para la caracterización y datación de su sistema defensivo. Dichos trabajos, financiados por el Concello da Fonsagrada, nos han permitido validar las hipótesis de partida y relacionar este recinto con otros localizados en el oriente galaico y occidente asturiano.

Palabras ClaVe: Ejército romano, campamento, noroeste peninsular, Cordillera Cantábrica, prospección arqueológica, teledetección.

\section{A PENAPARDA (A FONSAGRADA, LUGO - SANTALLA, ASTURIAS): INTERVENCIÓN ARQUEOLÓXICA NUN RECINTO CAMPAMENTAL ROMANO NO OCCIDENTE DA CORDILLEIRA CANTÁBRICA}

\section{RESUMO}

Neste traballo preséntanse os resultados da intervención arqueolóxica realizada en 2017 no xacemento de A Penaparda, un recinto campamental en forma de naipe de aproximadamente 10 ha situado entre os concellos de A Fonsagrada (Lugo) e Santalla (Asturias). Partindo dunha prospección arqueolóxica previa das Serras de Ouroso-Penouta con recurso a teledetección, esta campaña contemplou o recoñecemento integral das estruturas arqueolóxicas tanto en superficie como por teledetección, a prospección artefactual e por metalodetección dun sector do sitio e a apertura dunha sondaxe exploratoria para a caracterización e datación do seu sistema defensivo. Estes traballos foron financiados polo Concello da Fonsagrada, e permitíronnos validar as hipóteses de partida e relacionar este recinto con outros localizados no oriente galaico e occidente asturiano.

Palabras Clave: exército romano, campamento, noroeste peninsular, Cordillera Cantábrica, prospección arqueolóxica, teledetección.

\section{A PENAPARDA (A FONSAGRADA, LUGO - SANTALLA, ASTURIAS): ARCHAEOLOGICAL STUDY OF A ROMAN CAMP IN THE WESTERNMOST AREA OF THE CANTABRIAN MOUNTAINS}

\begin{abstract}
This paper presents the results of the archaeological campaign carried out in 2017 at the archaeological site of A Penaparda, a playing-card shaped Roman camp (ca. 10 ha) located on the border between A Fonsagrada (Lugo) and Santalla (Asturias). Following a previous archaeological survey of the Ouroso-Penouta Mountains where remote sensing techniques were used, this campaign comprised the integral survey of the archaeological structures -both on the surface and using remote sensing tools-, the artefact and metal surveying of some sections of the site, and the excavation of an exploratory trench to better characterise and date the sites' defences. These tasks, financed by the Concello da Fonsagrada, allowed us to validate our initial hypotheses about the site and to relate this enclosure with other camps located in Eastern Galicia and western Asturias.

KEY WORDS: Roman army, camp, NW Iberia, Cantabrian Mountains, archaeological survey, remote sensing.
\end{abstract}


Recibido/Received: 30/07/2019

Aceptado/Accepted: 30/01/2020

$\mathrm{E}$ 1 colectivo de investigación Romanarmy.eu se formó en 2015 sobre la base de una colaboración activa y horizontal entre distintos profesionales relacionados con el estudio, gestión y divulgación del Patrimonio Cultural. Entre sus cometidos se encuentra el de ahondar, a través de la Arqueología, en el proceso de transformación vivido por los paisajes en el noroeste peninsular a finales de la Edad del Hierro con motivo de la irrupción del estado romano ${ }^{1}$. En este sentido, una de sus principales señas distintivas ha sido la identificación, caracterización y estudio de evidencias arqueológicas relacionables con la presencia militar romana en esta amplia región -Galicia, Norte de Portugal, Asturias, León y Zamora- con recurso a metodologías en las que explora el potencial de diversas técnicas de teledetección ${ }^{2}$. Con todo, debe entenderse que estas acciones recientes hunden sus raíces en una trayectoria de investigación arqueológica que se remon-

\footnotetext{
1 Rebeca Blanco-Rotea, José Manuel Costa-García, João Fonte, David González Álvarez, Andrés Menéndez Blanco, Manuel Gago Mariño y Valentín Álvarez Martínez, "RomanArmy.eu: A multivocal research project on the Roman army presence in NW Iberia from the margins of Academia", The European Archaeologist, 50 (2016), págs. 72-76.

2 José Manuel Costa-García, "Rediscovering the Roman Conquest of the North-western Iberian Peninsula”, en M. Fernández-Götz and N. Roymans (eds.), Conflict Archaeology. Materialities of Collective Violence from Prehistory to Late Antiquity, Oxford, Routledge, 2017, págs. 141-151; José Manuel CosTA-GARCía, João Fonte y Manuel GaGo Mariño, "The reassessment of the Roman military presence in Galicia and Northern Portugal through digital tools: archaeological diversity and historical problems", Mediterranean Archaeology and Archaeometry, 19.3 (2019), págs. 17-49; José Manuel Costa-GarcíA, Andrés Menéndez Blanco, David González Álvarez, Manuel Gago Mariño, João Fonte, Rebeca Blanco-Rotea y Valentín Álvarez Martínez, "The Presence of the Roman Army in North-Western Hispania: New Archaeological Data from Ancient Asturias and Galicia”, en C. S. Sommer and S. Matešić (eds.), Limes XXIII. Proceedings of the 23 ${ }^{\text {rd }}$ International Limes Congress in Ingolstadt 2015, Vol. 2, Mainz, Nünnerich-Asmus, 2018, págs. 903-910; Andrés MenÉndez Blanco, David GonzÁlez Álvarez, José Manuel Costa García, João Fonte, Manuel Gago Mariño y Valentín Álvarez Martínez, "Seguindo os passos do exército romano: uma proposta metodológica para a deteção de assentamentos militares romanos no Noroeste Peninsular", en L. Rosas, A. C. Sousa, and H. Barreira (eds.), Genius Loci: lugares e significados $\mid$ places and meanings, Vol. 2, Porto, CITCEM - Centro de Investigação Transdisciplinar “Cultura, Espaço e Memória”, 2017, págs. 67-79; José Manuel Costa-García y João FonTE, "Scope and limitations of airborne LiDAR technology for the detection and analysis of Roman military sites in Northwest Iberia", en V. Mayoral Herrera, C. Parcero-Oubiña, and P. Fábrega-Álvarez (eds.), Archaeology and Geomatics. Harvesting the benefits of 10 years of training in the Iberian Peninsula (2006-2015), Leiden, Sidestone Press, 2017, págs. 57-73.
} 


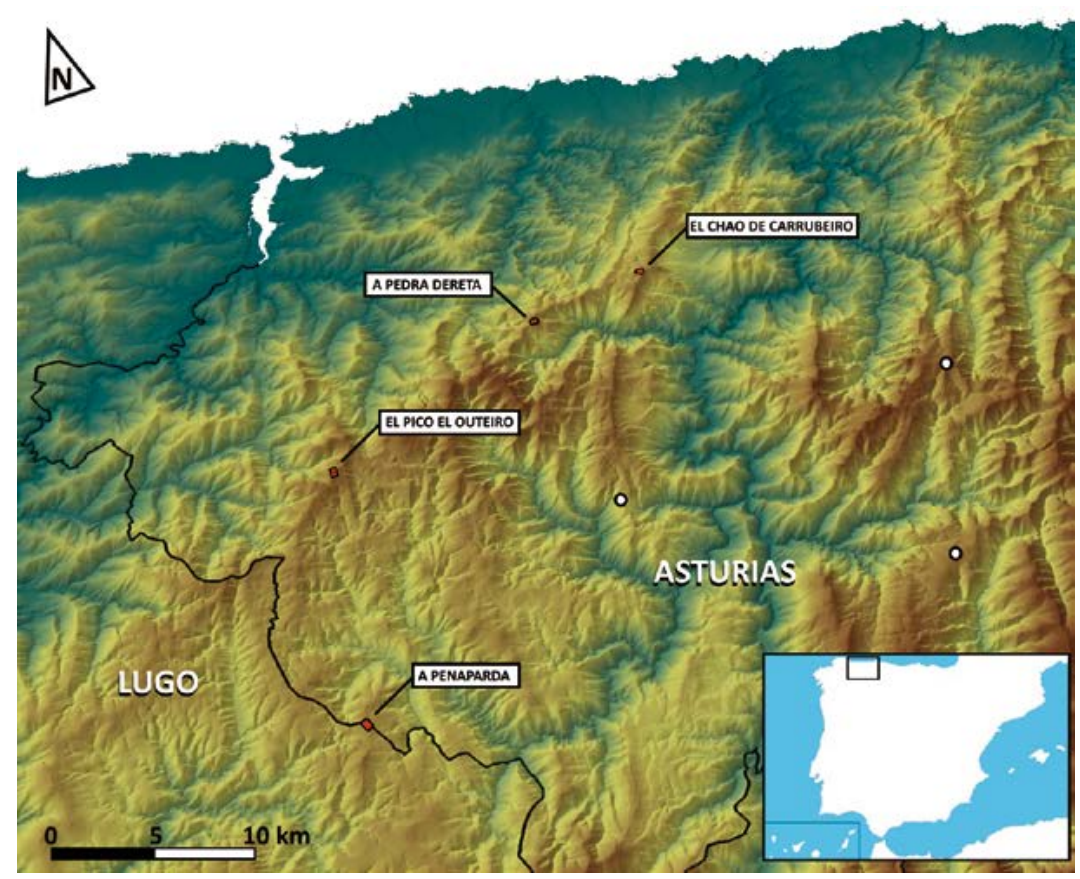

Fig. 1. Localización de A Penaparda dentro del conjunto de recintos de los cordales Penouta-Ouroso. En blanco, otros recintos localizados en la zona. MDT-LiDAR de $5 \mathrm{~m}$ facilitado por el CNIG-IGN.

ta, al menos, una década atrás ${ }^{3}$. Esta, a su vez, se inserta en el contexto general de auge y renovación metodológica de los estudios de Arqueología militar romana en la península ibérica que se viene fraguando desde finales del siglo pasado ${ }^{4}$.

\footnotetext{
3 David González Álvarez, Andrés Menéndez Blanco y Valentín Álvarez Martínez, "El campamento de Moyapán (Ayande, Asturias)", Férvedes: Revista de investigación, 5 (2008), págs. 363-371; Andrés MenÉndez Blanco, David González Álvarez, Valentín Álvarez Martínez y José Ignacio JiMÉNez ChAPARRo, "Propuestas de prospección de bajo coste para la detección de campamentos romanos de campaña. El área occidental de la Cordillera Cantábrica como caso de estudio", Munibe Antropologia - Arkeologia, 64 (2013a), págs. 175-197.

${ }^{4}$ Eduardo Peralta Labrador, "Los campamentos romanos de campaña (castra aestiva): evidencias científicas y carencias académicas", Nivel Cero. Revista del grupo arqueológico Attica, 10 (2002), págs. 49-87; Ángel Morillo Cerdán (ed.), Arqueología Militar Romana en Hispania, Madrid, CSIC; Polifemo, 2002; Ángel Morillo Cerdán (ed.), Arqueología militar romana en Hispania II: Producción y abastecimiento en el ámbito militar, León, Servicio de Publicaciones de la Universidad de León, 2006; Jorge Camino Mayor, Eduardo Peralta Labrador y José Francisco Torres Martínez (eds.), Las Guerras Ástur-Cántabras, Gijón, KRK Ediciones, 2015; Bartomeu Vallori MárquEZ, Juan Pedro Bellón Ruíz y Carmen Rueda GaLÁn, Accampamenti, guarnigioni e assedi durante la Seconda Guerra Punica e la conquista romana (secoli III-I aC): prospettive archeologiche, Roma, Edizioni Quasar di Severino Tognon, 2019; Ángel Morillo Cerdán, Norbert Hanel y Esperanza Martín Hernández (eds.), Limes XX. Estudios sobre la frontera romana, Madrid, CSIC; Polifemo, 2009.
} 
Estos avances nos han permitido diseñar una estrategia operativa para la prospección sistemática de amplias regiones del noroeste peninsular $\mathrm{y}$, en particular, de sus áreas montañosas. En el transcurso de estas actividades se produjo, a finales de 2015, el descubrimiento del recinto de A Penaparda (A Fonsagrada, Lugo / Santalla, Asturias) en una zona donde ya se habían identificado con anterioridad indicios de presencia militar romana ${ }^{5}$ (fig. 1). El procesado informático de las nubes de puntos LiDAR facilitadas por el Instituto Geográfico Nacional $(\mathrm{IGN})^{6}$ para Galicia Oriental (2009/2016) y Asturias (2012) permitió identificar unas estructuras cuya naturaleza arqueológica fue avalada más tarde in situ. El descubrimiento fue inmediatamente notificado a las autoridades competentes en materia de protección del Patrimonio Cultural de ambas $\mathrm{CCAA}^{7}$ y dado a conocer públicamente poco tiempo después juntamente con otros hallazgos ${ }^{8}$. En octubre de 2017 se desarrolló la primera intervención arqueológica en el lugar con el fin de avanzar en la caracterización y definición crono-funcional del recinto 9 .

\section{Contexto}

A Penaparda es una elevación (856 msnm) situada en las estribaciones orientales de A Serra da Sendiña/Barbeitos, siendo la aldea de A Trapa (San Cibrán, A Fonsagrada), a tan solo $400 \mathrm{~m}$ al $\mathrm{O}$ en línea recta, el núcleo habitado más próximo.

\footnotetext{
5 Andrés Menéndez Blanco, David González Álvarez, Valentín Álvarez Martínez y José Ignacio JimÉnez ChapARro, "La Sierra de Penouta y el cordal d'Ouroso: una línea de avance del ejército romano en el occidente cantábrico", en J. Camino Mayor, E. Peralta Labrador, and J. F. Torres Martínez (eds.), Las Guerras Ástur-Cántabras, Gijón, KRK Ediciones, 2015, págs. 261-268.

6 Centro Nacional de Información Geográfica (CNIG), Centro de Descargas [en línea], disponible en $<$ http://centrodedescargas.cnig.es/CentroDescargas/> [Consulta 22/07/2019].

7 Conseyería d'Educación y Cultura (Principado de Asturias, Reg. Entrada 2015010000123416) y Consellería de Cultura, Educación e Ordenación Universitaria (Rexistro Xeral da Xunta de Galicia, entrada 27252/RX 2493552, 09/12/2015).

8 José Manuel Costa-García, João Fonte, Manuel Gago Mariño, Andrés Menéndez Blanco y Valentín Álvarez Martínez, "Hallazgos arqueológicos recientes para el estudio de la presencia militar romana en el oriente gallego", Gallaecia, 35 (2017), págs. 39-70.

9 José Manuel Costa-García, Estudio arqueológico del recinto de A Penaparda (A Fonsagrada, Lugo). Memoria Final, Santiago de Compostela, DXPC, Cód. SXPA ED 102A 2017/479-0, 2019. Esta campaña se desarrolló gracias al respaldo económico del Concello de A Fonsagrada y al apoyo logístico tanto del Grupo de Investigación Síncrisis de la Universidade de Santiago de Compostela (USC), como del Instituto de Ciencias del Patrimonio (Incipit), perteneciente al Consejo Superior de Investigaciones Científicas (CSIC). Este apoyo cristalizó en el marco de los proyectos posdoctorales "On war, on peace: re-evaluating the impact of the Roman military presence in the Lower Rhine, Britain and NW Iberia through Archaeology" (ED481B 2016/117-0), de J. M. Costa-García, y "The archaeological landscapes of the Roman frontier: comparative perspectives on resources exploitation, social change and imperialism through a non-invasive methodology" (IN606B-2016/002), de J. Fonte, financiados gracias al programa de ayudas de la Xunta de Galicia a través de la Secretaría Xeral de Universidades y la Axencia GAIN. Queremos agradecer también la colaboración del grupo de investigación Ciencia do Sistema Terra (USC), encabezado por Antonio Martínez Cortizas. Por último, esta intervención no podría haberse llevado a buen término sin el trabajo sobre el terreno de Manuel Gago Mariño y Valentín Álvarez Martínez.
} 
Desde esta posición se controlan los hondos valles que, en dirección S-N, dibujan los arroyos de As Corradas y Candesa, afluentes del río Agüeira, quien a su vez lo es del Navia.

En la actualidad resulta muy complicado apreciar sobre el terreno las estructuras arqueológicas, muy allanadas por efecto del laboreo agrícola. La fotografía aérea histórica nos permite apreciar que el sector oriental del mismo, en territorio asturiano, se encuentra prácticamente arrasado desde al menos la segunda mitad del siglo XX, a lo que debemos sumar la reforestación producida en tiempos más recientes ${ }^{10}$. Afortunadamente, las visualizaciones obtenidas gracias al procesado informático de las nubes de puntos LiDAR suministradas por el IGN-CNIG nos permitieron reconstruir la planta del asentamiento militar, así como reconocer algunos elementos constructivos significativos, como son las entradas en clauicula situadas en el sector central de los lienzos meridional y septentrional ${ }^{11}$. Estos elementos morfo-tipológicos, unidos a un más detenido análisis del patrón de asentamiento del yacimiento, nos permitieron identificar positivamente el recinto como un campamento militar romano de carácter temporal $^{12}$.

Como apuntábamos más arriba, el hallazgo de asentamientos de este tipo se ha multiplicado en el noroeste peninsular en tiempos recientes. En otros trabajos hemos debatido ya su importancia a la hora de articular nuevas narrativas acerca de la conquista y ocupación de las distintas áreas de esta extensa región en los siglos II-I a. C. ${ }^{13}$, por lo que no nos detendremos ahora en un análisis que excede, con mucho, los objetivos de este artículo. Cabe señalar, pues, que A Penaparda no es un recinto aislado ya que al E, en los cordales de Ouroso-Penouta, se han podido identificar tres recintos campamentales -El Pico el Outeiro, A Pedra Dereta,

\footnotetext{
${ }^{10}$ En los fotogramas de la Serie B del Vuelo Americano (1956-57) puede apreciarse la mitad occidental del recinto. En las fotografías más modernas solo se distinguen en menor medida algunas partes del perímetro defensivo, en particular el esquinal ONO (Quinquenal 2003, PNOA 2006, 2009 y 2011; Google Inc. 16/09/2001, 20/08/2010).

${ }^{11}$ Costa-García y Fonte, "Scope and limitations...”, págs. 57-73; Costa-García, et al., "Hallazgos arqueológicos recientes...”, págs. 39-70.

${ }_{12}$ Rebecca H. Jones, Roman Camps in Britain, Stroud, Amberley Publishing, 2012; Rebecca H. Jones, Roman Camps in Scotland, Edinburgh, Society of Antiquaries of Scotland, 2011; Jeffrey L. DAviES y Rebecca H. Jones, Roman Camps in Wales and the Marches, Cardiff, University of Wales Press, 2006; Michel Reddé, Raymond Brulet, Rudolf Fellmann, Jan Kees Haalebos y Sigmar Von Schnurbein, Les fortifications militaires, Bordeaux, Ausonius, 2006.

${ }^{13}$ Costa-García, "Rediscovering the Roman Conquest...”, págs. 141-151; Costa-García, Fonte y Gago Mariño, “The reassessment...”, págs. 17-49; González Álvarez, D., Costa-García, J. M., Menéndez Blanco, A., Fonte, J., Álvarez Martínez, V., Blanco-Rotea, R. y Gago Mariño, M., "La presencia militar romana en el noroeste ibérico hacia el cambio de era: estado actual y retos de futuro", en B. Vallori Márquez, J. P. Bellón Ruíz y C. Rueda Galán (eds.), Accampamenti, guarnigioni e assedi durante la Seconda Guerra Punica e la conquista romana (secoli III-I aC): prospettive archeologiche, Roma, Edizioni Quasar di Severino Tognon, 2019, págs. 127-138.
} 
El Chao de Carrubeiro-y una pequeña fortificación tipo castellum -también en El Pico el Outeiro- ${ }^{14}$ (fig. 1). Habida cuenta de su morfología, similar extensión, patrón de asentamiento y regular emplazamiento en las sierras, es muy posible que exista una conexión directa entre A Penaparda y los dos recintos de mayor tamaño de este conjunto -El Pico el Outeiro y A Pedra Dereta $-{ }^{15}$. Hacia el O, en fechas próximas al descubrimiento del recinto que nos ocupa se halló también $\mathrm{O}$ Monte de Ventín (Pol, Lugo) ${ }^{16}$, de dimensiones algo superiores. Con todo, su relativa proximidad permitiría establecer una conexión con las llanuras del interior de Lugo. Aquí, si exceptuamos las teorías alrededor del origen militar de la capital provincial ${ }^{17}$, el rastreo de la presencia militar romana en tiempos tempranos había resultado poco productivo.

En el extremo occidental de la Cordillera Cantábrica nos encontramos con los recintos de Moyapán, El Chao y La Resiell ${ }^{18}$ hacia el E, y los de A Granda das Xarras (Ibias, Asturias / Candín, León) y A Recacha (Navia de Suarna, Lugo), intervenidos arqueológicamente en tiempos recientes ${ }^{19}$, hacia el S. Aunque en principio estas fortificaciones no guardan una relación directa con A Penaparda, estimamos que cualquier avance producido en su estudio contribuye a generar un

\footnotetext{
${ }^{14}$ MenÉndez Blanco, et al., "La Sierra de Penouta...", págs. 261-268; Andrés Menéndez Blanco, David González Álvarez, Valentín Álvarez Martínez y José Ignacio Jiménez Chaparro, "Campamentos romanos de campaña en el Occidente de Asturias", Excavaciones Arqueológicas en Asturias 2007-2012. En el centenario del descubrimiento de la caverna de La Peña de Candamo, Oviedo, Consejería de Educación, Cultura y Deporte del Principado de Asturias, 2013b, págs. 245-251; Alfonso MenÉNDEZ GRANDA y Estefanía SÁNCHEZ HidALGo, "Campaña de sondeos arqueológicos en el campamento de época romana del Pico El Outeiro Zarrado (Taramundi-Villanueva de Oscos)", en P. León Gasalla (ed.), Excavaciones Arqueológicas en Asturias 2013-2016, Oviedo, Consejería de Educación y Cultura, Principado de Asturias - Ediciones Trabe, 2018, págs. 283-292.

${ }^{15}$ Costa-García, "Rediscovering the Roman Conquest...", págs. 141-151.

${ }^{16}$ Costa-García, et al., "Hallazgos arqueológicos recientes ...", págs. 39-70.

${ }^{17}$ Rodríguez Colmenero, A., "Lucus Augusti (Lugo). Introducción histórica y arqueológica", en M. P. García-Bellido (ed.), Los campamentos romanos en Hispania (27 a.C.-192 d.C): el abastecimiento de moneda, Vol. I Madrid, CSIC, 2006, págs 29-60.

${ }^{18}$ Luís Blanco Vázquez, Patricia SuÁrez Manjón y Alejandro Sánchez Díaz, "Moyapán: hallazgos arqueológicos en las defensas de un campamento romano del occidente de Asturias", Revista de Arqueología, 369 (2012), págs. 26-33; GonzÁlez Álvarez, et al., "El campamento de Moyapán...”, págs. 363371; Costa-García, "Rediscovering the Roman Conquest...", págs. 141-151.

19 MenÉndez Granda y Sánchez Hidalgo, "Campaña de sondeos...", págs. 283-292; Almudena OreJAS, Francisco Javier. SÁnchez-Palencia, Alejandro Beltrán, José Antonio Ron, Luís Francisco LóPez, Brais X. Currás, Damián Romero, Elena Zubiaurre, Juan Luís Pecharromán y Luís Arboledas, "Conquista, articulación del territorio y explotación de recursos en el límite entre el convento lucense y el de los ástures (Proyecto IVGA)", en J. Camino Mayor, E. Peralta Labrador, and J. F. Torres Martínez (eds.), Las Guerras Ástur-Cántabras, Gijón, KRK Ediciones, 2015, págs. 247-260; Almudena Orejas, Francisco Javier SÁnchez-Palencia y José Antonio Ron TeJedo, "Proyecto IVGA: conquista, dominación y explotación minera entre el conventus de los astures y el lucense", en P. León Gasalla (ed.), Excavaciones Arqueológicas en Asturias 2013-2016, Oviedo, Consejería de Educación y Cultura, Principado de Asturias - Ediciones Trabe, 2018, págs. 239-252.
} 
impacto significativo en la comprensión general de la presencia militar romana en esta zona montañosa y, por extensión, en el noroeste ibérico.

\section{Metodología de ESTUdio}

Tras un detallado análisis de las características morfológicas y distintos grados de conservación de los asentamientos militares romanos de carácter temporal ${ }^{20}$, estimamos oportuno aplicar durante esta primera fase de estudio del recinto de A Penaparda la metodología arqueológica que se describe en las siguientes líneas. Como norma general, el sistema de registro y documentación de la información durante la intervención arqueológica siguió los modelos planteados en Parcero Oubiña, et al. ${ }^{21}$. Todos los datos obtenidos fueron digitalizados y volcados en un Sistema de Información Geográfica (SIG) para facilitar su lectura e interpretación arqueológicas $^{22}$.

Por lo que respecta a la intervención propiamente dicha, se evaluó en primer lugar el estado de conservación y grado de visibilidad de las estructuras perimetrales previamente identificadas mediante teledetección ${ }^{23}$. La inspección ocular y documentación fotográfica de las defensas sobre el terreno se realizó siguiendo métodos convencionales en Arqueología ${ }^{24}$ y se complementó con un levantamiento

\footnotetext{
${ }^{20}$ Jaume M. Noguera, Eduard Ble y Pau Valdés Matías, "Metal Detecting for Surveying Marching Camps? Some Thoughts Regarding Methodology in Light of the Lower Ebro Roman Camps Project's Results", en L. Vagalinski and N. Sharankov (eds.), Limes XXII. Proceedings of the 22nd International Congress of Roman Frontier Studies Ruse, Bulgaria, September 2012, Sofía, NAIM-BAS, 2015, págs. 381-395; Jaume M. Noguera, Jordi Principal y Toni ÑACo Del Hoyo, "La actividad militar y la problemática de su reflejo arqueológico: el caso del Noreste de la Citerior (218-45 a.C.)", en Cadiou. F. and M. Navarro Caballero (eds.), La guerre et ses traces. Conflits et sociétés en Hispanie à l'époque de la conquête romaine (IIIe-Ier s. a.C.), Bordeaux, Ausonius, 2014, págs. 31-56; Juan Pedro Bellón RuIZ, Carmen Rueda Galán, Miguel Ángel Lechuga Chica, Arturo Ruiz Rodríguez y Manuel Molinos Molinos, "Archaeological methodology applied to the analysis of battlefields and military camps of the Second Punic War: Baecula”, Quaternary International, 435, Part B (2017), págs. 81-97; Juan Pedro Bellón Ruiz, Carmen Rueda Galán, Miguel Ángel Lechuga Chica y María Isabel Moreno, “An archaeological analysis of a battlefield of the Second Punic War: The camps of the battle of Baecula", Journal of Roman Archaeology, 29 (2016), págs. 73-104; Klaus Grote, "Hedemünden (Lkr. Göttingen) - Mehr als nur ein römisches Mililärlager”, Archaologisches Korrespondenzblatt, 44 (2014); Sabine Hornung, "Auf den Spuren Iulius Caesars. Das römische Militärlager von Hermeskeil”, Jahrb. Kr. Trier-Saarburg, 2018 (2018), págs. 239-258; Jones, Roman Camps in Britain.

${ }^{21}$ César Parcero OubiÑa, Fidel Méndez y Rebeca Blanco-Rotea, El registro de la información en Intervenciones Arqueológicas, Santiago de Compostela, Laboratorio de Arqueoloxía e Formas Culturais (GIArPa), IIT, USC, 1999.

${ }^{22}$ Henry Chapman, Landscape Archaeology and GIS, Stroud, The History Press, 2009; James Conolly y Mark LAKE, Geographical Information Systems in Archaeology, Cambridge, Cambridge University Press, 2006.

${ }^{23}$ Costa-García, et al., "Hallazgos arqueológicos recientes ...”, págs. 39-70.

${ }^{24}$ María del Carmen Martínez LóPez, Contribución a un Sistema de Registro de Yacimientos Arqueológicos en Galicia, Santiago de Compostela, Universidad de Santiago de Compostela, 1997; Peter G. DoRRELL, Photography in Archaeology and Conservation, Cambridge, CUP, 2010.
} 


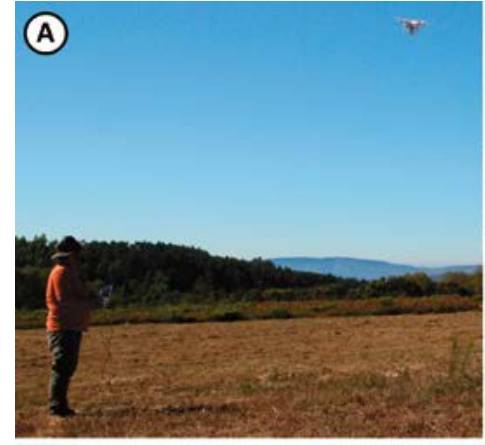

(C)

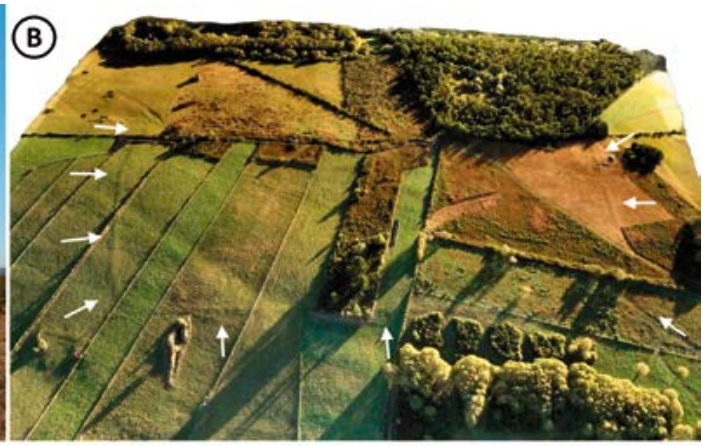

(D)
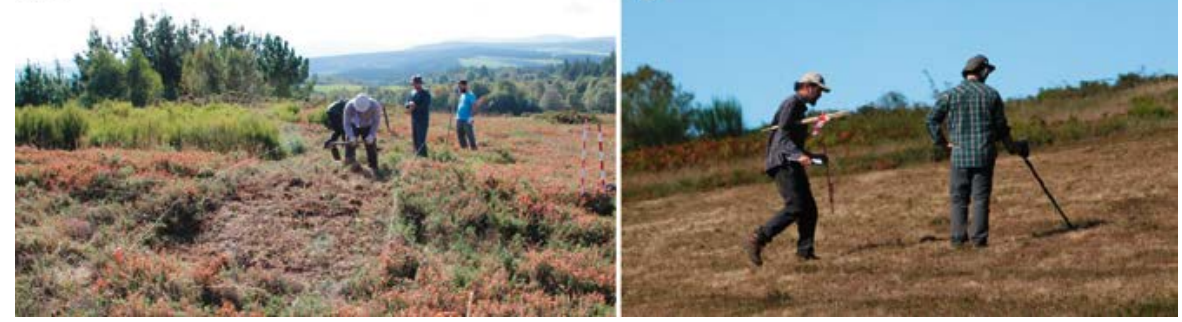

Fig. 2. Metodología de trabajo.

fotogramétrico general del yacimiento. Para ello se usó un dron DJI Phantom 3 Professional equipado con una cámara digital $4 \mathrm{~K}$ de 12 megapíxeles de resolución $^{25}$. La metodología de levantamiento 3D mejor adaptada a las necesidades de este proyecto fue la fotogrametría structure from motion ( $\mathrm{SfM}$ ), que nos permitió reconstruir secuencias tridimensionales a partir de pares de imágenes con superposición tomadas desde diferentes perspectivas ${ }^{26}$.

Así pues, se sobrevoló el yacimiento a una altitud uniforme de $75 \mathrm{~m}$ para tomar un conjunto de 268 fotografías cenitales (fig. 2A). Se dispusieron asimismo varios puntos de control sobre el terreno mediante el despliegue de dianas de lona impermeable numeradas correlativamente cuyas coordenadas absolutas se obtuvieron mediante el uso de un GPS (Global Positioning System) RTK (Real Time Ki-

\footnotetext{
${ }^{25}$ Debemos agradecer a Manuel Gago Mariño el completo trabajo de toma de fotografías aéreas con este equipo.

${ }^{26}$ Stefano Campana, "Drones in Archaeology. State-of-the-art and Future Perspectives", Archaeological Prospection, 24 (2017), págs. 275-296; James O’DriscOLL, "Landscape applications of photogrammetry using unmanned aerial vehicles", Journal of Archaeological Science: Reports, 22 (2018), págs. 32-44; Fabio Remondino y Stefano Campana, 3D Modeling in Archaeology and Cultural Heritage: Theory and Best Practices, Oxford, Archaeopress, 2014; G. Verhoeven, M. Doneus, Ch. Briese, F. Vermeulen, "Mapping by matching: a computer vision-based approach to fast and accurate georeferencing of archaeological aerial photographs", Journal of Archaeological Science, 39 (2012), págs. 2060-2070.
} 
nematic) submétrico (Leica System 1200). Las imágenes fueron procesadas en Agisoft Metashape ${ }^{\circledR}$ 1.5.1, un software basado en la fotogrametría digital automatizada y en algoritmos de reconstrucción en 3D de alta densidad a partir de múltiples puntos de vista. El modelo 3D obtenido fue georreferenciado usándose los citados puntos de control, obteniéndose finalmente un modelo digital de superficie (MDS) y una ortofotografía de 3,65 $\mathrm{cm}$ de resolución por píxel ${ }^{27}$.

Tras esta primera inspección del recinto y con el fin de facilitar el desarrollo de las restantes actividades arqueológicas, se desbrozó el monte bajo (principalmente tojo y brezo) que cubría las áreas de actuación prioritarias del proyecto, localizadas en el sector meridional del yacimiento. A continuación, se llevó a cabo un levantamiento fotogramétrico de esta zona de trabajo. A partir de las 127 fotografías cenitales tomadas a una altitud constante de $75 \mathrm{~m}$ fue posible obtener un MDS y una ortofotografía de 1,32 cm/píxel (fig. 2B).

De acuerdo con los principios más habituales de prospección arqueológica tanto en contextos intra-site (dentro del yacimiento) como off-site (fuera del sitio arqueológico $)^{28}$, durante la intervención se prospectó un área de aproximadamente 0,8 ha con el fin de recuperar cualquier indicio de cultura material que permitiese un mejor conocimiento, caracterización y datación del sitio. Para ello se delimitaron y georreferenciaron los límites de seis grandes áreas de prospección (AP), espacios que fueron a su vez subdivididos longitudinalmente en unidades artificiales más pequeñas. Esto permitió al equipo arqueológico realizar un barrido uniforme de cada uno de ellos con el fin de facilitar la identificación de cualquier material arqueológico en superficie.

Es sabido que uno de los principales elementos materiales que permiten la identificación positiva de asentamientos militares romanos son los objetos de metal relacionados con el equipamiento de los soldados ${ }^{29}$. Esta situación es par-

\footnotetext{
27 Recuérdese que la fotografía aérea proporcionada por el IGN tiene una resolución de 25-50 cm (INSTItuto Geográfico Nacional (IGN), Plan Nacional de Ortofotografia Aérea (PNOA) [en línea], disponible en $<$ http://pnoa.ign.es/> [Consulta 22/07/2019]). Igualmente, los modelos digitales del terreno (MDT) obtenidos a partir de datos LiDAR rara vez superan $1 \mathrm{~m}$ de resolución CoSTA-GARCÍA y FONTE, "Scope and limitations...”, págs. 57-73.

${ }_{28}$ Edward B. BAnning, Archaeological Survey, Manuals in Archaeology Method, Theory and Technique, New York, Kluwer Academic, 2002; Cristina CoRsı, Božidar SLAPŠAK y Frank Vermeulen, Good Practice in Archaeological Diagnostics. Non-invasive Survey of Complex Archaeological Sites, Cham, Springer, 2013; David Barreiro, "Sistemas de prospección arqueológica", en X. Amado (ed.), Inventario y Catalogación del Patrimonio Cultural. Módulo 3, Santiago de Compostela, Laboratorio de Arqueoloxía e Formas Culturais, IIT, USC, 2001, págs. 57-61.

29 Carmelo Fernández IBÁÑEz, "Post Vestigium Exercitus. Militaria romana en la región septentrional de la Península Ibérica durante la época Altoimperial”, en Á. Morillo Cerdán (ed.), Arqueología militar romana en Hispania II: producción y abastecimiento en el ámbito militar, León, Universidad de León, 2006, págs. 257-308; PERALTA LABRADOR, "Los campamentos romanos...”, págs. 49-87; Carmelo FernáNDEZ IBÁÑEZ, "Las armas del enemigo. Militaria romana de metal en la guerra cantábrica de Augusto", en
} 
ticularmente importante en el caso de las fortificaciones de carácter temporal, donde la presencia de elementos cerámicos suele ser puramente residual ${ }^{30}$. Con frecuencia, los magros niveles estratigráficos relacionables con la ocupación militar se encuentran completamente removidos y alterados por efecto de la actividad agraria o la reforestación, por lo que es solamente la dispersión de materiales de este tipo la que permite la identificación positiva de estos sitios arqueo$\operatorname{lógicos}^{31}$. Es por ello que, diversos sistemas de detección magnética han sido empleados de forma recurrente en el estudio de asentamientos militares romanos, tanto en la península ibérica como fuera de ella ${ }^{32}$.

Teniendo en cuenta estas experiencias previas, así como la nuestra propia en anteriores intervenciones ${ }^{33}$, diseñamos una estrategia destinada a la recuperación y salvaguarda de materiales metálicos adaptada a la normativa legal vigente en

J. Camino Mayor, E. Peralta Labrador, and J. F. Torres Martínez (eds.), Las Guerras Ástur-Cántabras, Gijón, KRK Ediciones, 2015, págs. 323-344; Eduardo Peralta Labrador, Jose Ángel Hierro Gárate y Emilio GuTIÉRREz CuENCA, "Las monedas de los campamentos romanos de campaña de las guerras cántabras del asedio de la Loma, Castillejo y Alambre", Lucentum, 30 (2011), págs. 151-172; Juan Pedro BELLÓNRUIZ,Arturo Ruíz RodRíGuez, Manuel MolinosMolinos, Carmen Rueda Galány Francisco Gómez Cabeza, La Segunda Guerra Púnica en la península ibérica Baecula: arqueología de una batalla, Jaén, Universidad de Jaén, 2015; Eduardo Peralta Labrador, "Equipamiento militar romano de la conquista de la antigua Cantabria", Sautuola: Revista del Instituto de Prehistoria y Arqueología Sautuola, 13 (2007), págs. 492-511; Bellón Ruiz, et al., "Archaeological methodology...”, págs. 81-97; Bellón RuIZ, et al., "An archaeological analysis ...", págs. 73-104.

30 Juan José CePEdA OCAMPo, “Los campamentos romanos de La Poza (Cantabria)", en Á. Morillo Cerdán (ed.), Arqueología militar romana en Hispania II: Producción y abastecimiento en el ámbito militar, León, Servicio de Publicaciones de la Universidad de León, 2006, págs. 683-690; Jorge Camino MaYor, "La línea de operaciones de la vía Carisa (Asturias y norte de León)", en J. Camino Mayor, E. Peralta Labrador, and J. F. Torres-Martínez (eds.), Las Guerras Ástur-Cántabras, Gijón, KRK Ediciones, 2015, págs. 217-237; Eduardo PERALTA LABRADOR, "La penetración del ejército romano por el interfluvio Pas-Besaya", en J. Camino Mayor, E. Peralta Labrador, and J. F. Torres-Martínez (eds.), Las Guerras Ástur-Cántabras, Gijón, KRK Ediciones, 2015, págs. 131-148.

${ }^{31}$ Noguera, Ble y Valdés Matías, "Metal Detecting for Surveying...”, págs. 853-860; Eduard Ble, Sandra Lacruz, Jaume M. Noguera y Pau Valdés Matías, "La Palma: Un campamento de Publio Cornelio Escipión ‘Africano' durante la Segunda Guerra Púnica en Iberia”, Ex novo: revista d'història $i$ humanitats, 7 (2011), págs. 105-132; José Antonio Ocharán LARrondo y Miguel UnZueta Portilla, "Andagoste (Cuartango, Álava): Un nuevo escenario de las guerras de conquista en el norte de Hispania", en Á. Morillo Cerdán (ed.), Arqueología Militar Romana en Hispania, Madrid, CSIC; Polifemo, 2002, págs. 311-321.

${ }^{32}$ Bellón Ruiz, et al., "An archaeological analysis...”, págs. 73-104; Noguera, Ble y Valdés Matías, "Metal Detecting for Surveying...", págs. 853-860; Frank Berger, Felix Bittmann, Michael GeschwinDE, Petra LönNe, Michael MeYer y Günther Moosbauer, "Die römisch-germanische Auseinandersetzung am Harzhorn (Ldkr. Northeim, Niedersachsen)", Germania, 88 (2010), págs. 313-402; MenÉNDEZ Granda y SánChez Hidalgo, "Campaña de sondeos arqueológicos...", págs. 203-292.

${ }^{33}$ Andrés Menéndez Blanco, José Manuel Costa-García, David González Álvarez, Valentín Álvarez Martínez, V. Álvarez Martínez y João Fonte, "Los campamentos romanos de Cueiru y El Xuegu la Bola na vía de La Mesa. Resultaos de la campaña del 2016”, en P. León Gasalla (ed.), Excavaciones Arqueológicas en Asturias 2013-2016, Oviedo, Consejería de Educación y Cultura, Principado de Asturias - Ediciones Trabe, 2018, págs. 273-282. 
la Comunidad Autónoma de Galicia en materia de Patrimonio Arqueológico ${ }^{34}$. Sirviéndonos de las áreas de prospección ya definidas se realizó un segundo barrido con un detector de metales de alta sensibilidad y precisión (Garrett AT Pro) (fig. 2D). Cada anomalía magnética documentada fue entonces balizada y georreferenciada. Seguidamente, se inspeccionó cada punto con el fin de identificar objetos en superficie. De producirse un resultado negativo, la pieza se encontraría en el subsuelo, por lo que se abrieron sondeos con unas dimensiones limitadas $(30 \times 30 \mathrm{~cm})$ para facilitar su recuperación. Lógicamente, durante su excavación se procedió a un minucioso registro estratigráfico siguiendo los principios y procedimientos ya explicados más arriba. Al identificarse las piezas, estas fueron fotografiadas y registradas in situ, procediéndose seguidamente a una nueva toma de coordenadas absolutas. Finalmente, los sondeos fueron cubiertos.

Con el objetivo de ahondar en el conocimiento de las estructuras perimetrales del recinto dentro de una secuencia estratigráfica fiable, se abrió un sondeo arqueológico de $10 \times 2 \mathrm{~m}$ en el lienzo SE (fig. 2C). Esta pequeña intervención se ajustó al método originalmente propuesto por Harris ${ }^{35}$ y más tarde revisado por otros autores ${ }^{36}$. Se tomaron asimismo varias muestras para datación absoluta por radiocarbono ${ }^{37}$ con el fin de definir con mayor precisión las fases de construcción, uso y abandono de las estructuras. Por último, se realizó un levantamiento fotogramétrico del sondeo a partir de 71 fotografías cenitales y oblicuas tomadas a $10 \mathrm{~m}$ de altitud, obteniéndose como resultado un MDS de $5 \mathrm{~mm} /$ píxel y una ortofotografía de 1,65 mm/píxel de resolución máxima.

\section{RESULTADOS}

\section{a) Reconocimiento y análisis de las estructuras perimetrales}

La prospección superficial y el levantamiento fotogramétrico realizados en 2017 nos han permitido definir con mayor exactitud la disposición en planta y el estado de conservación actual de las defensas perimetrales del recinto en sus diferentes sectores (fig. 3). De este modo, podemos apuntar que el asentamiento contaba con un perímetro defensivo en forma de naipe ligeramente irregular, toda

\footnotetext{
${ }^{34}$ Detectores de metales y otras técnicas análogas. Artigo 101, LEI 5/2016, do 4 de maio de 2016, do Patrimonio Cultural de Galicia.

${ }^{35}$ Edward C. Harris, Principles of Archaeological Stratigraphy (2 ${ }^{\text {nd }}$ Ed.), London \& San Diego, Academic Press, 1989.

36 Andrea Carandini, Historias en la Tierra. Manual de excavación arqueológica, Barcelona, Crítica, 1997; Gonzalo Ruíz Zapatero, "La excavación arqueológica”, en M. García-Díez and L. Zapata Peña (eds.), Métodos y Técnicas de análisis y estudio en arqueología prehistórica. De lo técnico a la reconstrucción de los grupos humanos, Bilbao, UPV, 2013, págs. 39-72.

${ }^{37}$ Clive OrTon, Sampling in Archaeology, Cambridge, Cambridge University Press, 2000; R. Ervin TAYLOR y Ofer BAR-Yosef, Radiocarbon Dating: An Archaeological Perspective, London, Routledge, 2014.
} 


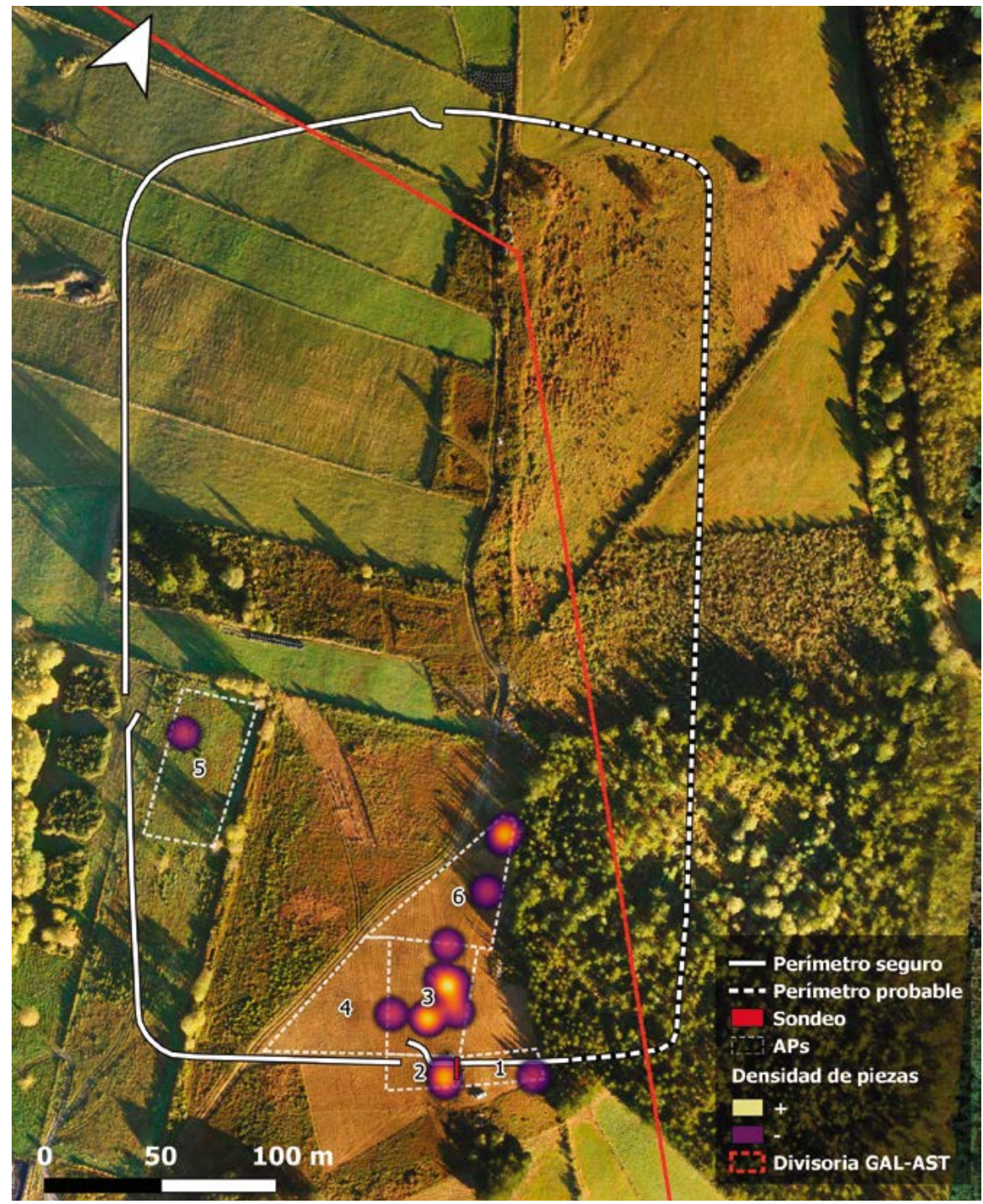

Fig. 3. A Penaparda 2017. Planta general del recinto sobre ortofotografía obtenida a partir del vuelo fotogramétrico realizado con dron por M. Gago y áreas de actuación.

vez que su eje menor (O SO-E NE) se estrecha a medida que nos desplazamos hacia el Sur (de 254 a $234 \mathrm{~m}$ ), mientras que el mayor (S SE-N NO) oscila entre los 398 y los $422 \mathrm{~m}$ por proyectarse el lienzo Norte ligeramente hacia el exterior. La fortificación toma como eje longitudinal la dorsal de la sierra, que desciende suavemente hacia el SS E desde el pico de A Penaparda, y ocupa a dos aguas sus 
laderas occidental y oriental. Como resultado, el recinto ocupa una superficie neta (a contar desde el exterior de sus parapetos) de 10,13 ha, estableciéndose en $6,6^{\circ}$ el valor medio de la pendiente del terreno al interior del mismo.

Como cabía esperar en un yacimiento de estas dimensiones, el grado de conservación y visibilidad de las estructuras es muy desigual a lo largo de los 1245 $\mathrm{m}$ de perímetro defensivo. En líneas generales, podemos afirmar que los sectores que se encuentran al $\mathrm{O}$ de la mencionada divisoria de aguas son los mejor preservados. Esto implica aproximadamente un $60 \%$ del trazado total que se localiza mayoritariamente en territorio gallego. Con todo, las visualizaciones LiDAR permiten documentar la posición de los esquinales orientales y reconstruir el trazado de buena parte del lienzo E.

\section{a.1) Lienzo $\mathrm{S}$}

Incluso antes de su desbroce, fue posible distinguir en este sector un lienzo rectilíneo por espacio de $162 \mathrm{~m}$. Se documentó un terraplén de 3,5-4 $\mathrm{m}$ de anchura y $0,2-0,3 \mathrm{~m}$ de altitud con respecto al suelo de uso al interior del recinto. De forma paralela al terraplén se identificó al exterior una depresión donde no solo se acumulaba más humedad, sino que además existía un crecimiento diferenciado de la vegetación: aquí abundaban las retamas (xestas), frente a la predominancia de tojos (toxos) y brezos (uces) en otras zonas.

Se confirmó asimismo sobre el terreno la existencia de un acceso en clavícula. Como suele ser común en el norte peninsular ${ }^{38}$, dicha solución se implementó mediante la prolongación de uno de los parapetos hacia el interior del recinto. El acceso, perfectamente apreciable en las visualizaciones LiDAR, se percibe con mayor dificultad en el modelo digital de superficie resultante del levantamiento fotogramétrico, lo que revela el acusado grado de deterioro que la estructura presenta en la actualidad (fig. 4).

Por último, a aproximadamente $20 \mathrm{~m}$ al $\mathrm{S}$ del parapeto se documentó otra posible estructura lineal que se desarrolla en dirección E-O. Con todo, no hemos podido establecer una relación directa entre esta y las defensas del campamento propiamente dichas.

\section{a.2) Esquinal $\mathrm{SO}$}

Este sector del recinto se encuentra muy afectado por los efectos de las recientes aradas con maquinaria pesada. De hecho, el esquinal, con un ángulo de apertura

\footnotetext{
38 José Manuel Costa-García, Arqueología de los asentamientos militares romanos en la Hispania altoimperial (27 a. C. - ca. 280 d. C.), tesis doctoral inédita, Santiago de Compostela, Universidade de Santiago de Compostela, 2013.
} 

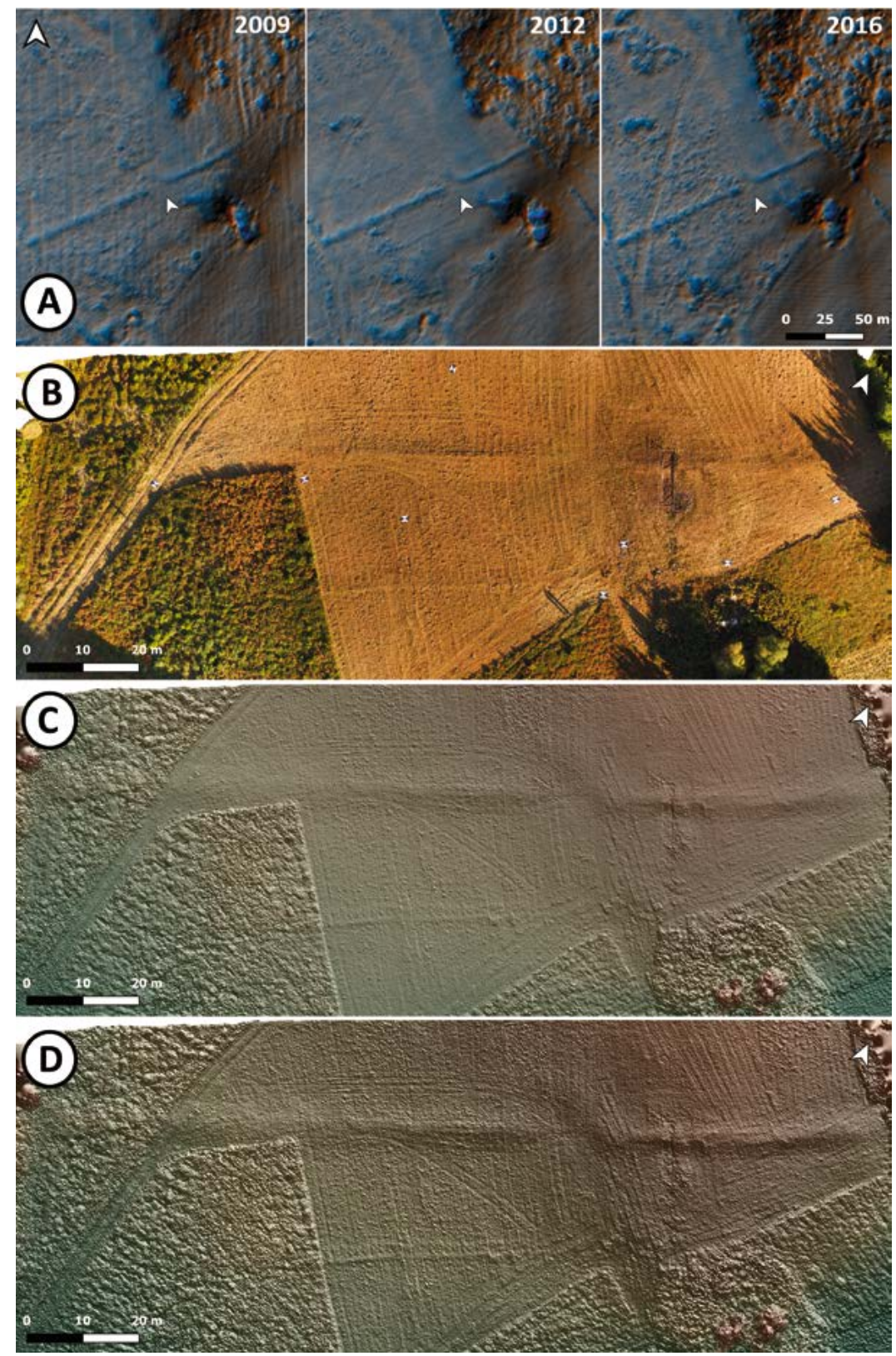

Fig. 4. Lienzo Sur. Visualizaciones obtenidas a partir de los datos LiDAR facilitados por el CNIG-IGN (A); ortofotografía realizada en 2017 a partir de los vuelos de M. Gago (B); Modelo Digital de Superficie (MDS) con sombreado y luz rasante desde el Norte: factor de exageración 1 (C) y 2,5 (D). 
de $90^{\circ}$, solo puede apreciarse gracias a los sutiles cambios de rasante en la pendiente del terreno.

\section{a.3) Lienzo O}

El estado de conservación de este lienzo es muy desigual a lo largo de sus 330 $\mathrm{m}$ de extensión. Al $\mathrm{S}$, las remociones recientes con maquinaria han desdibujado notablemente su trazado. En su sector central el antiguo terraplén ha sido además puntualmente empleado como linde parcelario. En las restantes áreas, destinadas a pradería, se percibe el parapeto como un elemento que interrumpe artificialmente la pendiente. Este alcanza aquí unos 4-5 metros de anchura, distinguiéndose igualmente una depresión al exterior.

En este lienzo debía localizarse igualmente un acceso lateral que se correspondiese con la prolongación del eje de la via principalis campamental. A aproximadamente $122 \mathrm{~m}$ de trazado del lienzo O (un 30\% de su trazado total) se documentó una interrupción y retranqueo del parapeto que podría corresponderse con el arranque de una clavícula. En cualquier caso, planteamos esta posibilidad como una hipótesis de trabajo.

\section{a.4) Esquinal $\mathrm{NO}$}

Este esquinal describe un ángulo más abierto que el anterior (unos $106^{\circ}$ ) por la ya mencionada proyección del Lienzo Norte. Aunque su registro gráfico sobre el terreno fue infructuoso, las fotografías aéreas tomadas con luz rasante nos permitieron obtener una impresión nítida de su localización y morfología.

\section{a.5) Lienzo $\mathrm{N}$}

Considerando el ángulo de apertura arriba señalado, este lienzo se extiende unos $100 \mathrm{~m}$ en dirección ENE hasta alcanzar el punto más alto y llano de la cumbre. El terraplén alcanza aquí 4-5 m de anchura por 0,1-0,2 m de altitud con respecto al espacio interior, mientras que al exterior se distingue una suave depresión. Aquí, a los pies de la peña que da nombre al yacimiento, se documentó otro acceso al recinto campamental. Como el primero, se encontraría protegido por una clavícula interior, pero esta estructura se encuentra en peor estado de conservación. A partir de este punto, el trazado de las defensas campamentales vira sensiblemente en dirección Este, pudiéndose distinguir durante otros $50 \mathrm{~m}$ ladera abajo antes de desdibujarse por completo.

\section{a.6) Sector oriental}

Como señalábamos, la reconstrucción de este sector debe fiarse a los métodos de teledetección, puesto que ni la orografía -la pendiente es más acusada aquí 
que en la ladera occidental- ni la actividad antrópica ha permitido su adecuada conservación. De este modo, se documentan algunos tramos del lienzo E en la fotografía aérea y en las visualizaciones gracias al contraste entre los antiguos parapeto y foso. La prolongación de este eje permite situar los esquinales orientales, si bien el SE se intuye además por un corte en la pendiente natural.

\section{b) Sondeo exploratorio}

Tras evaluar el estado de conservación del perímetro defensivo del yacimiento, estimamos oportuno abrir un sondeo exploratorio en la mitad oriental del lienzo $\mathrm{S}$, a aproximadamente $10 \mathrm{~m}$ al NE del acceso en clavícula. Como ya se ha dicho, su finalidad fue la de avanzar en la caracterización de las defensas perimetrales del recinto, así como la toma de muestras para su datación por ${ }^{14} \mathrm{C}$.

\section{b.1) Secuencia estratigráfica}

Siguiendo las directrices de la Dirección Xeral de Patrimonio Cultural (DXPC) $)^{39}$, el sondeo fue excavado respetándose las estructuras halladas, de modo que no llegó a agotarse la potencia arqueológica en algunos sectores. Durante este proceso se registraron 15 unidades estratigráficas (UEs). Posteriormente se analizó el conjunto de relaciones entre dichas UEs con el fin de establecer una secuencia estratigráfica que sintetizamos en las siguientes líneas en el sentido inverso al de su excavación, desde las más antiguas hasta las más modernas (fig. 5).

En el primer horizonte podemos apreciar que se practica un corte (UE013) en el terreno natural localizado en el sector centro-meridional del sondeo (UE007) (fig. 6A). Este corte, de aproximadamente $1,8 \mathrm{~m}$ de anchura y unos $20 \mathrm{~cm}$ de profundidad, moldea hacia el $\mathrm{N}$ la arena gruesa fruto de la descomposición de la roca básica (pizarras grises con cloritoide), mientras que en su extremo $\mathrm{S}$ fractura un afloramiento de la misma roca.

Hacia el interior del recinto, en el extremo $\mathrm{N}$ del sondeo, se apreció la existencia de un nivel fruto de la descomposición de la roca básica (UE014), equiparable a la UE007. Sobre ella se documentó asimismo otro depósito de tierra húmica que no mostraba evidencias claras de acción antrópica y que parece corresponderse con el suelo natural (UE011).

Sobre estos niveles se asentó la estructura del parapeto, que estaba compuesta en primer lugar por una camada de tierra de color amarillento y piedras menudas. Hacia el interior del recinto, esta primera capa de tierra se corresponde con la UE012, mientras que hacia el exterior contamos con la UE015. El parapeto propiamente

\footnotetext{
39 Dependiente de la Consellería de Cultura e Turismo de la Xunta de Galicia.
} 

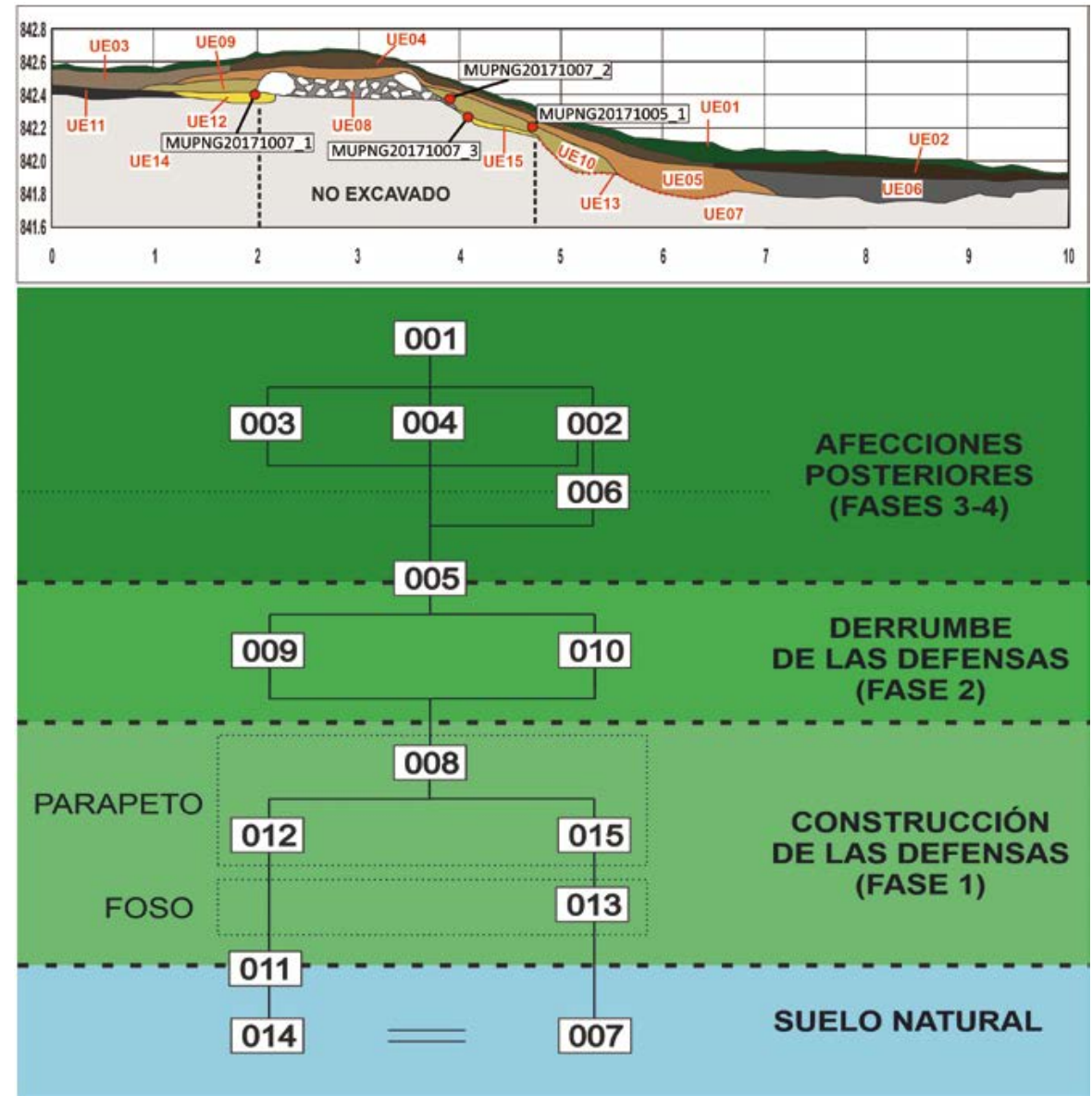

Fig. 5. Sección explicativa del sondeo exploratorio (arriba) y matrix Harris de la misma (abajo).

dicho-agger/vallum-(UE008) está formado por la acumulación de tierra y piedras de diverso tamaño - probablemente extraídos del foso-. Hacia el interior del recinto se documentó la existencia de una hilera de piedras de tamaño medio delimitando la estructura (fig. 6B). Aunque cabe pensar en una solución similar hacia el exterior, esta fachada se encontraba completamente desbarrigada. Ello no nos permite tampoco establecer la anchura total de la estructura, que en la actualidad alcanza los $1,8 \mathrm{~m}$. Por lo que respecta a la altura del parapeto, en este sondeo conservaba una altura de 15-20 cm con respecto al suelo interior (UE012) y de $70 \mathrm{~cm}$ hacia el exterior si tomamos como referente el punto más profundo del foso (UE013).

Entre foso y parapeto existía un espacio de aproximadamente $1 \mathrm{~m}$ en el que se localizó la ya mencionada UE015. Esta capa de tierra se encontraba totalmente 

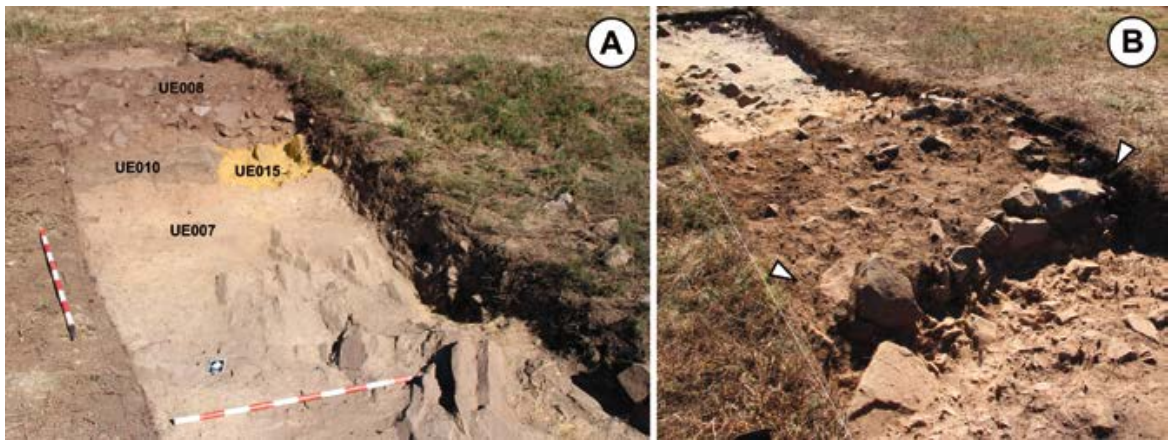

Fig. 6. Estructuras defensivas documentadas en el sondeo desde el Sur (A) y el Norte (B). Apréciese la presencia del foso en primer término (UE007) y de las UE que formarían el parapeto (UE008 y UE015) (A) y de la hilera que delimita este último hacia el interior del recinto (B).

comprimida y en ella se incrustaban numerosas piedras, muchas de ellas buzadas hacia el $\mathrm{S}$. Todo parece indicar que esta situación sería el resultado del derrumbe de la estructura sobre un espacio de berma que antecedería a un foso-foss $a$ - poco profundo y con sección en $\mathrm{U}$.

El segundo horizonte lo integran aquellas unidades relacionadas con el derumbe del parapeto. Esta destrucción es mucho más notoria en el sector externo del recinto que en el interior por la propia pendiente del terreno y la presencia del foso en este último ámbito. Así, se aprecia un notable paquete formado por piedras de diferente tamaño y tierra marrón-amarillenta (UE10) cuyo buzamiento refleja el desmoronamiento de la fachada exterior, cubriendo parcialmente el foso (UE013). Hacia el interior, la mencionada hilada de piedras delimitando el parapeto (UE008) se encuentra parcialmente combada y un nivel de tierra marrón-amarillenta y piedras pequeñas (UE009), de composición similar a la UE010, cubre el espacio que se extiende hacia el límite $\mathrm{N}$ del sondeo.

El tercer horizonte se relaciona con las primeras afecciones sobre el parapeto ya derrumbado. Así, la UE005, de composición muy similar a las UEs 009 y 010, se extiende por casi todo el sondeo, alcanzando una mayor potencia en el área centro-meridional, donde la pendiente del terreno habría favorecido el arrastre de materiales. Cubriéndola, en el área $\mathrm{S}$ del sondeo, se encuentra un depósito de tierra muy oscura, cenicienta, y con presencia de piedras de gran tamaño (UE006).

Finalmente, el cuarto horizonte se relaciona con las actividades agropecuarias más recientes. Tres depósitos se documentaron bajo la cubierta vegetal (UE001), diferenciados por su desigual cromatismo y composición (UEs 002, 003 y 004). El único elemento de cultura material (PZE-001) se recuperó en la UE001, siendo un pequeño fragmento informe de hierro. 


\section{b.2) Dataciones por radiocarbono}

Para la datación de los campamentos romanos, la estrategia de muestreo óptima pasa por la obtención de sedimentos o carbones en contextos sellados relacionables, bien con el momento de construcción de las defensas, bien con el de su colmatación y sellado ${ }^{40}$. En el primer caso, las muestras deberán tomarse en las cotas inferiores de los parapetos; en el segundo, el objetivo de atención primaria serán los depósitos inferiores que rellenan los fosos. En teoría, no debería transcurrir mucho tiempo entre el momento de fundación y el de abandono en asentamientos ocupados de forma puntual o estacional. De acuerdo con algunas menciones en las fuentes grecolatinas ${ }^{41}$, los campamentos serían intencionalmente destruidos durante su evacuación para evitar la reocupación de los mismos por el enemigo. Con todo, no sabemos hasta qué punto esta instrucción era una práctica extendida o simplemente una recomendación.

Como ya se ha expresado más arriba, se optó por no comprometer la integridad estructural de las defensas durante esta primera fase de estudio siguiendo las recomendaciones de la DXPC. No se tomaron muestras en el parapeto porque este comenzó a documentarse a una cota muy próxima a la superficie y la presencia de raíces superficiales era demasiado elevada.

De este modo, planteamos la siguiente estrategia de muestreo. Por un lado, pretendimos datar con precisión el momento de derrumbe del parapeto hacia el exterior y la colmatación parcial del foso, por lo que se tomaron dos muestras en la UE010 -de las que solo una fue datada finalmente-. En segundo lugar, se tomó una muestra en la UE012 y otra en la UE015 con un idéntico objetivo: datar dos estratos (tal vez una única capa originariamente) sobre los que se asentaba el mismo parapeto, bien porque fuesen resultado de una deposición intencionada, bien porque se correspondiesen con el sustrato original en el momento de construirse la fortificación.

Dichas muestras fueron secadas al aire y pretratadas ${ }^{42}$ antes de remitirse a los laboratorios de Beta Analytic (Miami, EE. UU). Allí fueron sometidas a un tratamiento con ácido previo a la medición por Espectrometría de Masas acoplado a Acelerador (AMS). Las edades obtenidas fueron calibradas por los técnicos de Beta Analytic por medio del software Oxcal $4.1^{43}$ en base a la curva

\footnotetext{
40 Menéndez Granda y Sánchez Hidalgo, “Campaña de sondeos...”, págs. 283-292; Orejas, et al., “Conquista, articulación del territorio...”, págs. 247-260; HoRnung, “Auf den Spuren Iulius Caesars. Das römische Militärlager von Hermeskeil”; Grote, "Hedemünden (Lkr. Göttingen) - Mehr als nur ein römisches Mililärlager", págs. 261-269.

${ }^{41}$ Joseph, BJ 5.3.4

${ }^{42}$ Agradecemos a Rebeca Tallón Armada (Grupo Ecopast, Departamento de Edafoloxía e Química Agrícola, USC) su colaboración y ayuda en este proceso.

${ }^{43}$ Christopher Bronk Ramsey y Sharen Lee, "Recent and Planned Developments of the Program OxCal”, Radiocarbon, 55.3-4 (2013), págs. 720-730.
} 


\begin{tabular}{|c|c|c|c|c|c|}
\hline MUESTRA & $\begin{array}{c}\text { REF. } \\
\text { LABORATORIO }\end{array}$ & UE & $\begin{array}{c}\text { TIPO DE } \\
\text { MATERIAL } \\
\text { MUPNG20171005_1 }\end{array}$ & $\begin{array}{c}\text { FECHA CALIBRADA } \\
\text { PROB. 95,4\% }\end{array}$ & $\begin{array}{c}\text { FECHA CALIBRADA } \\
\text { PROB. 68,2\% }\end{array}$ \\
\hline MUPNG20171007_1 & Beta-523996 & UE012 & $\begin{array}{c}\text { Sedimento } \\
\text { orgánico } \\
\text { orgánico }\end{array}$ & $\begin{array}{c}\text { No datada } \\
\text { Cal AD } \\
(926-795 \text { cal BP })\end{array}$ & $\begin{array}{c}\text { Cal AD } \\
1083-1150 \\
(867-800 \text { cal BP })\end{array}$ \\
\hline MUPNG20171007_2 & Beta-522331 & UE010 & $\begin{array}{c}\text { Sedimento } \\
\text { orgánico }\end{array}$ & $\begin{array}{c}\text { Cal AD 598-669 } \\
(1352-1281 \\
\text { cal BP })\end{array}$ & $\begin{array}{c}\text { Cal AD 620-659 } \\
\text { (1330-1291 } \\
\text { cal BP })\end{array}$ \\
\hline MUPNG20171007_3 & Beta-522330 & UE015 & $\begin{array}{c}\text { Sedimento } \\
\text { orgánico }\end{array}$ & $\begin{array}{c}\text { Cal AD 422-574 } \\
(1528-1376 \\
\text { cal BP })\end{array}$ & $\begin{array}{c}\text { Cal AD 430-516 } \\
\text { (1520-1434 } \\
\text { cal BP) }\end{array}$ \\
\hline
\end{tabular}

Fig. 7. Resultados de las dataciones por radiocarbono.

de calibración publicada por Reimer, et al..$^{44}$. De forma resumida, los resultados se recogen en la fig. 7 .

De este modo podemos reconstruir dos procesos deposicionales diferentes. La cara exterior del parapeto se desbarrigó en un momento indeterminado de los siglos V-VI d. C., sellando entonces la UE015 - berma- y cubriendo parcialmente la UE013 -foso-. Muy poco tiempo después, posiblemente en la primera mitad del siglo VII, hemos podido datar la UE010, el potente paquete de derrumbe que sella definitivamente este espacio. Sin embargo, desconocemos si el desmantelamiento de las estructuras se debió a un proceso natural de deterioro o si fue resultado de una actividad antrópica destinada a nivelar el terreno con alguna finalidad.

En el interior del recinto se recordará que el parapeto (UE008) se conservaba algo mejor, presentando todavía una hilera de delimitación. Asimismo, el derrumbe (UE009) era aquí mucho menos potente y cubría a la UE012, cuyo sellado se puede datar en los siglos XI-XII. A diferencia de lo visto en el espacio anterior, parece que el colapso de la estructura habría sido menos violento en este sector, aspecto favorecido por la más suave pendiente. No será hasta la transición entre la Edad Media temprana y la Edad Media plena que la cara interior de la estructura quede finalmente colmatada.

Como ha ocurrido en muchos otros casos, las estructuras antiguas muy posiblemente sirvieron también aquí como elemento de referencia para la parcelación y el laboreo agrícola. La fotografía aérea histórica de los años 1945-6 (Vuelo Americano Serie A) y 1956-7 (Vuelo Americano Serie B) nos permite comprobar

\footnotetext{
${ }_{44}$ Paula J. ReImer, et al., "IntCal13 and Marine13 Radiocarbon Age Calibration Curves 0-50,000 Years cal BP”, Radiocarbon, 55.4 (2013), págs. 1869-1687.
} 
que, en efecto, a mediados del siglo XX -cuando el terreno todavía se dedicaba al cereal-el parapeto meridional del campamento se correspondía todavía con el linde entre dos parcelas. No será hasta tiempos recientes, en el contexto de las profundas transformaciones vividas por el mundo rural -mecanización, transformación de los sistemas de explotación del paisaje, concentración parcelaria, etc.que este hecho comience a difuminarse. Todo esto viene a reforzar la idea de la estructura arqueológica sirviendo como límite entre dos espacios con dinámicas diferenciadas.

\section{c) Resultados de la prospección}

De las seis áreas de prospección (AP) establecidas en el sector meridional del recinto (fig. 3), cinco se delimitaron para cubrir el espacio de tránsito definido a partir de la identificación del acceso campamental. Por su parte, la AP5, más alejada, debía servir como elemento de contraste, ya que no solo se localiza en una zona diferente del yacimiento, sino que presentaba además un mayor grado de acción antrópica en el momento de producirse la intervención.

Si bien la prospección artefactual no permitió documentar la presencia de cultura material de ningún tipo (cerámica, líticos, etc.), la detección magnética parecía arrojar inicialmente resultados más prometedores. Una vez descartados los restos de alambres y otros elementos de indudable cronología subactual, se exploraron las restantes anomalías magnéticas. Como resultado de ello, se recuperaron 15 piezas metálicas, 6 de ellas en superficie y las 9 restantes mediante la apertura de micro-sondeos exploratorios de $30 \times 30 \mathrm{~cm}$. Estas últimas se documentaron formando parte de un mismo paquete que se correspondería con tierra de labrada, hoy en día dedicada a pradería.

Los materiales, en su mayoría férricos, presentaban un elevado grado de corrosión y fragmentación, lo que en algunos casos dificultó enormemente su caracterización crono-tipológica. Aquellos elementos para los que ha podido ofrecerse una datación nos remiten a un contexto marcadamente contemporáneo, con especial incidencia en los siglos XIX-XX (numerario reciente, cartuchería, tornillería, restos de maquinaria). Esta situación revela que nos encontramos ante un contexto verdaderamente complicado para la conservación de los restos metálicos de mayor antigüedad. La elevada acidez del sustrato natural, la secular actividad agropecuaria - que implica procesos de remoción, arada, rozas y uso de fertilizantes o abonos- son las más probables explicaciones para esta situación.

Cuando comparamos este registro arqueológico con los resultados de las prospecciones llevadas a cabo por el colectivo Romanarmy.eu en otros yacimientos usando la misma metodología (fig. 8), resulta llamativo que, pese a ser A Penaparda uno de los lugares donde se ha prospectado una mayor superficie, no solo 
el volumen de piezas metálicas recuperadas es el más bajo del conjunto, sino que además no se ha podido documentar tampoco ningún material que pueda adscribirse de forma segura a época romana. En este sentido debemos tener en cuenta los resultados arrojados por el vecino campamento de El Pico el Outeiro (Taramunde-Vilanova d'Ozcos, Asturias), que se sitúa a apenas $15 \mathrm{~km}$ al $\mathrm{N}$ en línea recta y que presenta similares características morfotipológicas, un mismo patrón de asentamiento y semejante composición del sustrato natural. Este yacimiento fue recientemente prospectado con recurso a la metalodetección sin que fuese posible recuperar ningún elemento metálico susceptible de ser datado en época romana -no ha trascendido el volumen total de hallazgos $-{ }^{45}$.

\begin{tabular}{|c|c|c|c|c|c|c|c|}
\hline YACIMIENTO & $\begin{array}{c}\text { HA } \\
\text { PROSPECTADAS }\end{array}$ & $\mathrm{N}^{\mathrm{o}} \mathrm{AN}$ & $\mathrm{N}^{\mathrm{o}} \mathrm{PZ}$ & $\mathrm{AN} / \mathrm{HA}$ & $\mathrm{PZ} / \mathrm{HA}$ & PZ RoM & $\begin{array}{c}\text { PZ RoM } \\
\%\end{array}$ \\
CU-16 & 0,47 & 140 & 154 & 297,87 & 327,66 & 3 & 1,95 \\
\hline XB-16 & 0,82 & 35 & 37 & 42,68 & 45,12 & 2 & 5,41 \\
\hline PNG-17 & 0,81 & 24 & 15 & 28,8 & 18,52 & 0 & 0,00 \\
\hline SAS-17 & 0,22 & 344 & 461 & 1563,64 & 2095,45 & 13 & 2,82 \\
\hline PLB-18 & 0,51 & 105 & 98 & 205,88 & 192,16 & 9 & 9,18 \\
\hline
\end{tabular}

Fig. 8. Resultados de la prospección por metalodetección en A Penaparda (PNG-17) en comparación con otros sitios estudiados con la misma metodología: Cueiru (CU-16) y

El Xuegu la Bola (XB-16) (Asturias); Penedo dos Lobos (PLB-18) (Galicia); y

Carrecastro-Sasamón (SAS-17). Nótese la escasa presencia de materiales que pueden adscribirse con seguridad al período romano en todos los casos.

Dado el bajo número de piezas recuperadas, es difícil extraer datos de utilidad con respecto a distribución dentro del recinto. Es cierto que se aprecia una mayor densidad de anomalías magnéticas y de piezas siguiendo el eje viario mayor del recinto. Este se desarrollaría en dirección S SE-N NO, siguiendo una cota uniforme al $\mathrm{O}$ del punto más elevado del cordal montañoso, donde nos encontramos con afloramientos rocosos. Dada la concentración de materiales contemporáneos en esta zona, todo parece indicar que el cordal ha seguido siendo un espacio de tránsito también en tiempos recientes. En este sentido, sorprende la casi total ausencia de evidencias en las AP 4 y 5 , situadas ladera abajo.

\section{CONCLUSIONES}

A la espera de que futuras intervenciones en el yacimiento nos permitan muestrear los contextos estratigráficos más antiguos del mismo, podemos concluir que las estructuras arqueológicas detectadas en 2015 por teledetección no son en

\footnotetext{
45 Menéndez Granda y SÁnchez Hidalgo, “Campaña de sondeos arqueológicos...”, págs. 283-292.
} 
ningún caso recientes, pudiendo remitirse a un horizonte cronológico anterior a los siglos V-VI d. C. Si bien el análisis morfotipológico del recinto (planta en forma de naipe, entradas en clavícula, sistema defensivo agger-fossa) ya permitía sostener su antigüedad ${ }^{46}$, no podemos determinar en qué momento exacto se erigieron las estructuras. La estrategia destinada a datar su colmatación, que partía a su vez de la hipótesis de un desmantelamiento inmediato e intencional, no ha dado el resultado previsto. Así pues, solo futuros estudios podrán clarificar esta incógnita, así como aclarar si esta tardía colmatación es un fenómeno puntual o si se trata de una tendencia.

Debemos señalar, no obstante, que otras fortificaciones romanas próximas sí han podido datarse con mayor exactitud. En el ya mencionado campamento de El Pico el Outeiro ${ }^{47}$, las muestras de carbones tomadas en los niveles inferiores de la colmatación de sus fosos -más profundos que los de A Penaparda- arrojan unas dataciones que nos remiten a un horizonte de entre mediados del siglo I a. C. y mediados del I d. C. De igual modo, las analíticas realizadas para A Recacha (Navia de Suarna, Lugo) y A Granda das Xarras (Ibias, Asturias / Candín, León) ${ }^{48}$, nos remiten a un horizonte anterior al cambio de Era.

Lógicamente, el estudio detallado y datación exacta de estos hallazgos relativamente recientes nos permitirá construir narrativas históricas sólidas acerca de la presencia militar romana en una región que se había caracterizado, hasta la fecha, por la carencia de indicios arqueológicos en este sentido. Sin embargo, por el momento son muy escasos los recintos que pueden encuadrarse cronológicamente con precisión en el noroeste peninsular. En este sentido, conviene hacer una interesante puntualización metodológica. Desde que a mediados de la década de 1990 comenzase a crecer exponencialmente el número de asentamientos militares romanos identificados en el norte peninsular, el principal método para la caracterización y datación de estos yacimientos ha sido la recuperación, en contextos arqueológicos, de metalistería y, en particular, de numerario ${ }^{49}$. Asimismo, en los cordales montañosos de la cordillera cantábrica, la presencia militar romana se ha contextualizado automáticamente con los escenarios bélicos de época augustea en relación con las guerras cántabro-astures (29-19 a. C.). Sin embargo, a medida que nos desplazamos hacia el occidente, no solo la conservación del metal

\footnotetext{
${ }^{46}$ Costa-García, et al., "Hallazgos arqueológicos recientes...", págs. 39-70.

47 Menéndez Granda y Sánchez Hidalgo, “Campaña de sondeos arqueológicos...”, págs. 283-292.

48 Orejas, et al., “Conquista, articulación del territorio...”, págs. 247-260; OrEJAS, et al., "Proyecto IVGA ...”, págs. 239-252.

49 Peralta Labrador, et al., "Las monedas de los campamentos...”, págs. 151-172; Peralta Labrador, "Los campamentos romanos...", págs. 49-87; CAMINo MAYOR, "La línea de operaciones...", págs. 217237; María Paz García-Bellido (ed.), Los campamentos romanos en Hispania (27 a.C.-192 d.C). El abastecimiento de moneda, Madrid, CSIC; Polifemo, 2006.
} 
comienza a convertirse en un aspecto problemático, como hemos visto ${ }^{50}$, sino que empezamos a perder el cómodo paraguas de las narrativas históricas heredadas ${ }^{51}$. De este modo y pese a sus limitaciones, los métodos de datación físico-química deben contemplarse como la estrategia más fiable para la adecuada datación de los campamentos romanos en la zona que nos ocupa.

\section{BIBLIOGRAFÍA}

Banning, Edward B., Archaeological Survey, Manuals in Archaeology Method, Theory and Technique, New York, Kluwer Academic, 2002.

Barreiro, David, "Sistemas de prospección arqueológica", en X. Amado (ed.), Inventario y Catalogación del Patrimonio Cultural. Módulo 3, Santiago de Compostela, Laboratorio de Arqueoloxía e Formas Culturais, IIT, USC, 2001, págs. 57-61.

Bellón Ruiz, Juan Pedro; Rueda Galán, Carmen; Lechuga Chica, Miguel Ángel y Moreno, María Isabel, "An archaeological analysis of a battlefield of the Second Punic War: The camps of the battle of Baecula", Journal of Roman Archaeology, 29 (2016), págs. 73-104.

Bellón Ruiz, Juan Pedro; Rueda Galán, Carmen; Lechuga Chica, Miguel Ángel; Ruiz Rodríguez, Arturo y Molinos Molinos, Manuel, "Archaeological methodology applied to the analysis of battlefields and military camps of the Second Punic War: Baecula", Quaternary International, 435, Part B (2017), págs. 81-97.

Bellón Ruiz, Juan Pedro; Ruíz Rodríguez, Arturo; Molinos Molinos, Manuel; Rueda Galán, Carmen y Gómez Cabeza, Francisco, La Segunda Guerra Púnica en la península ibérica Baecula: arqueología de una batalla, Jaén, Universidad de Jaén, 2015.

Berger, Frank; Bittmann, Felix; Geschwinde, Michael; Lönne, Petra; Meyer, Michael y Moosbauer, Günther "Die römisch-germanische Auseinandersetzung am Harzhorn (Ldkr. Northeim, Niedersachsen)", Germania, 88 (2010), págs. 313-402.

Blanco-Rotea, Rebeca; Costa-García, José Manuel; Fonte, João; González Álvarez, David; Menéndez Blanco, Andrés; Gago Mariño, Manuel y Álvarez Martínez, Valentín, "RomanArmy.eu: A multivocal research project on the Roman army presence in NW Iberia from the margins of Academia", The European Archaeologist, 50 (2016), págs. 72-76.

Blanco Vázquez, Luís; Suárez Manjón, Patricia y Sánchez Díaz, Alejandro, “Moyapán: hallazgos arqueológicos en las defensas de un campamento romano del occidente de Asturias", Revista de Arqueología, 369 (2012), págs. 26-33.

Ble, Eduard; Lacruz, Sandra; Noguera, Jaume M. y Valdés Matías, Pau, "La Palma: Un campamento de Publio Cornelio Escipión ‘Africano' durante la Segunda Guerra Púnica en Iberia”, Ex novo: revista d'història i humanitats, 7 (2011), págs. 105-32.

\footnotetext{
${ }_{50}$ En este sentido, es necesario recalcar la absoluta excepcionalidad de Penedo dos Lobos, donde el numerario nos permite remitirnos a un horizonte de la década de 20 a. C. (Colectivo Romanarmy.eu, El campamento romano de Penedo dos Lobos revela la presencia militar romana más antigua documentada en Galicia [en línea], disponible en <http://romanarmy.eu/2018/08/28/s-cantabro-astures-ocampamento-romano-de-penedo-dos-lobos-revela-a-presenza-militar-romana-mais-antiga-documentada-en-galicia/> [Consulta 22/07/2019]).

${ }^{51}$ Costa-García, Fonte y Gago Mariño, “The reassessment...”, págs. 17-49.
} 
Bronk Ramsey, Christopher y Lee, Sharen, "Recent and Planned Developments of the Program OxCal”, Radiocarbon, 55.3-4 (2013), págs. 720-730.

Camino Mayor, Jorge, "La línea de operaciones de la vía Carisa (Asturias y norte de León)", en J. Camino Mayor, E. Peralta Labrador, y J. F. Torres-Martínez (eds.), Las Guerras Ástur-Cántabras, Gijón, KRK Ediciones, 2015, págs. 217-237.

Camino Mayor, Jorge; Peralta Labrador, Eduardo y Torres Martínez, José Francisco (eds.), Las Guerras Ástur-Cántabras, Gijón, KRK Ediciones, 2015.

Campana, Stefano, "Drones in Archaeology. State-of-the-art and Future Perspectives", $A r$ chaeological Prospection, 24 (2017), págs. DOI 10.1002/arp.569.

Carandini, Andrea, Historias en la Tierra. Manual de excavación arqueológica, Barcelona, Crítica, 1997.

Centro Nacional de Información Geográfica (CNIG), Centro de Descargas [en línea], disponible en $<\mathrm{http}$ ://centrodedescargas.cnig.es/CentroDescargas/> [Consulta 22/07/2019].

Cepeda Ocampo, Juan José, "Los campamentos romanos de La Poza (Cantabria)", en Á. Morillo Cerdán (ed.), Arqueología militar romana en Hispania II: Producción y abastecimiento en el ámbito militar, León, Servicio de Publicaciones de la Universidad de León, 2006, págs. 683-690.

Chapman, Henry, Landscape Archaeology and GIS, Stroud, The History Press, 2009.

Colectivo Romanarmy.eu, El campamento romano de Penedo dos Lobos revela la presencia militar romana más antigua documentada en Galicia [en línea], disponible en $<\mathrm{http}$ ://romanarmy. eu/2018/08/28/s-cantabro-astures-o-campamento-romano-de-penedo-dos-lobos-revela-a-presenza-militar-romana-mais-antiga-documentada-en-galicia/> [Consulta 22/07/2019]).

Conolly, James y Lake, Mark, Geographical Information Systems in Archaeology, Cambridge, Cambridge University Press, 2006.

Corsi, Cristina; Slapšak, Božidar y Vermeulen, Frank, Good Practice in Archaeological Diagnostics. Non-invasive Survey of Complex Archaeological Sites, Cham, Springer, 2013.

Costa-García, José Manuel, Arqueología de los asentamientos militares romanos en la Hispania altoimperial (27 a. C. - ca. 280 d. C.), tesis doctoral inédita, Santiago de Compostela, Universidade de Santiago de Compostela, 2013.

Costa-García, José Manuel, "Rediscovering the Roman Conquest of the North-western Iberian Peninsula", en M. Fernández-Götz y N. Roymans (eds.), Conflict Archaeology. Materialities of Collective Violence from Prehistory to Late Antiquity, Oxford, Routledge, 2017, págs. 141-151.

Costa-García, José Manuel, Estudio arqueológico del recinto de A Penaparda (A Fonsagrada, Lugo). Memoria Final, Santiago de Compostela, DXPC, Cód. SXPA ED 102A 2017/479$0,2019$.

Costa-García, José Manuel y Fonte, João, "Scope and limitations of airborne LiDAR technology for the detection and analysis of Roman military sites in Northwest Iberia", en V. Mayoral Herrera, C. Parcero-Oubiña, y P. Fábrega-Álvarez (eds.), Archaeology and Geomatics. Harvesting the benefits of 10 years of training in the Iberian Peninsula (2006-2015), Leiden, Sidestone Press, 2017, págs. 57-73.

Costa-García, José Manuel; Fonte, João y Gago Mariño, Manuel, "The reassessment of the Roman military presence in Galicia and Northern Portugal through digital tools: archaeo- 
logical diversity and historical problems", Mediterranean Archaeology and Archaeometry, 19.3 (2019), págs. 17-49. Doi: doi.org/10.5281/zenodo.3457524

Costa-García, José Manuel; Fonte, João; Gago Mariño, Manuel; Menéndez Blanco, Andrés y Álvarez Martínez, Valentín, "Hallazgos arqueológicos recientes para el estudio de la presencia militar romana en el oriente gallego", Gallaecia, 35 (2017), págs. 39-70.

Costa-García, José Manuel; Menéndez Blanco, Andrés; González Álvarez, David; Gago Mariño, Manuel; Fonte, João; Blanco-Rotea, Rebeca y Álvarez Martínez, Valentín, "The Presence of the Roman Army in North-Western Hispania: New Archaeological Data from Ancient Asturias and Galicia”, en C. S. Sommer y S. Matešić (eds.), Limes XXIII. Proceedings of the $23^{\text {rd }}$ International Limes Congress in Ingolstadt 2015, Vol. 2, Mainz, Nünnerich-Asmus, 2018, págs. 903-910.

Davies, Jeffrey L. y Jones, Rebecca H., Roman Camps in Wales and the Marches, Cardiff, University of Wales Press, 2006.

Dorrell, Peter G., Photography in Archaeology and Conservation, Cambridge, CUP, 2010.

Fernández Ibáñez, Carmelo, "Post Vestigium Exercitus. Militaria romana en la región septentrional de la Península Ibérica durante la época Altoimperial”, en Á. Morillo Cerdán (ed.), Arqueología militar romana en Hispania II: producción y abastecimiento en el ámbito militar, León, Universidad de León, 2006, págs. 257-308.

Fernández Ibáñez, Carmelo, "Las armas del enemigo. Militaria romana de metal en la guerra cantábrica de Augusto", en J. Camino Mayor, E. Peralta Labrador, y J. F. Torres Martínez (eds.), Las Guerras Ástur-Cántabras, Gijón, KRK Ediciones, 2015, págs. 323-344.

Flavio Josefo, La guerra de los judios. Edición de J. M. Nieto Ibáñez (2 Vols.), Madrid, Gredos, 1997.

García-Bellido, María Paz (ed.), Los campamentos romanos en Hispania (27 a.C.-192 d.C). El abastecimiento de moneda, Madrid, CSIC; Polifemo, 2006.

González Álvarez, David; Costa-García, José Manuel; Menéndez Blanco, Andrés; Fonte, João; Álvarez Martínez, Valentín; Blanco-Rotea, Rebeca, y Gago Mariño, Manuel, "La presencia militar romana en el noroeste ibérico hacia el cambio de era: estado actual y retos de futuro", en B. Vallori Márquez, J. P. Bellón Ruíz y C. Rueda Galán (eds.), Accampamenti, guarnigioni e assedi durante la Seconda Guerra Punica e la conquista romana (secoli III-I $a C)$ : prospettive archeologiche, Roma, Edizioni Quasar di Severino Tognon, 2019, págs. 127-138.

González Álvarez, David; Menéndez Blanco, Andrés y Álvarez Martínez, Valentín, "El campamento de Moyapán (Ayande, Asturias)", Férvedes: Revista de investigación, 5 (2008), págs. 363-371.

Grote, Klaus, "Hedemünden (Lkr. Göttingen) - Mehr als nur ein römisches Mililärlager", Archaologisches Korrespondenzblatt, 44 (2014), págs. 239-258.

Harris, Edward C., Principles of Archaeological Stratigraphy (2 ${ }^{\text {nd }}$ Ed.), London \& San Diego, Academic Press, 1989.

Hornung, Sabine "Auf den Spuren Iulius Caesars. Das römische Militärlager von Hermeskeil”, Jahrb. Kr. Trier-Saarburg, 2018 (2018), págs. 261-269.

Instituto Geografico Nacional (IGN), Plan Nacional de Ortofotografía Aérea (PNOA) [en línea], disponible en $<$ http://pnoa.ign.es/ $>$ [Consulta 22/07/2019]. 
Jones, Rebecca H., Roman Camps in Scotland, Edinburgh, Society of Antiquaries of Scotland, 2011.

Jones, Rebecca H., Roman Camps in Britain, Stroud, Amberley Publishing, 2012.

Martínez López, María Del Carmen, Contribución a un Sistema de Registro de Yacimientos Arqueológicos en Galicia, Santiago de Compostela, Universidad de Santiago de Compostela, 1997.

Menéndez Blanco, Andrés; Costa-García, José Manuel; González Álvarez, David; Álvarez Martínez, Valentín; Álvarez Martínez, V. y Fonte, João, "Los campamentos romanos de Cueiru y El Xuegu la Bola na vía de La Mesa. Resultaos de la campaña del 2016", en P. León Gasalla (ed.), Excavaciones Arqueológicas en Asturias 2013-2016, Oviedo, Consejería de Educación y Cultura, Principado de Asturias - Ediciones Trabe, 2018, págs. 273-282.

Menéndez Blanco, Andrés; González Álvarez, David; Álvarez Martínez, Valentín y Jiménez Chaparro, José Ignacio, "Campamentos romanos de campaña en el Occidente de Asturias", Excavaciones Arqueológicas en Asturias 2007-2012. En el centenario del descubrimiento de la caverna de La Peña de Candamo, Oviedo, Consejería de Educación, Cultura y Deporte del Principado de Asturias, 2013b, págs. 245-251.

Menéndez Blanco, Andrés; González Álvarez, David; Álvarez Martínez, Valentín y Jiménez Chaparro, José Ignacio, "La Sierra de Penouta y el cordal d'Ouroso: una línea de avance del ejército romano en el occidente cantábrico", en J. Camino Mayor, E. Peralta Labrador, y J. F. Torres Martínez (eds.), Las Guerras-Ástur-Cántabras, Gijón, KRK Ediciones, 2015, págs. 261-268.

Menéndez Blanco, Andrés; González Álvarez, David; Álvarez Martínez, Valentín y Jiménez Chaparro, José Ignacio, "Propuestas de prospección de bajo coste para la detección de campamentos romanos de campaña. El área occidental de la Cordillera Cantábrica como caso de estudio", Munibe Antropologia - Arkeologia, 64 (2013a), págs. 175-197.

Menéndez Blanco, Andrés; González Álvarez, David; Costa García, José Manuel; Fonte, João; Gago Mariño, Manuel y Álvarez Martínez, Valentín, "Seguindo os passos do exército romano: uma proposta metodológica para a deteção de assentamentos militares romanos no Noroeste Peninsular", en L. Rosas, A. C. Sousa, y H. Barreira (eds.), Genius Loci: lugares e significados $\mid$ places and meanings, Vol. 2, Porto, CITCEM - Centro de Investigação Transdisciplinar "Cultura, Espaço e Memória”, 2017, págs. 67-79.

Menéndez Granda, Alfonso y Sánchez Hidalgo, Estefanía, "Campaña de sondeos arqueológicos en el campamento de época romana del Pico El Outeiro Zarrado (Taramundi-Villanueva de Oscos)", en P. León Gasalla (ed.), Excavaciones Arqueológicas en Asturias 2013-2016, Oviedo, Consejería de Educación y Cultura, Principado de Asturias - Ediciones Trabe, 2018, págs. 283-292.

Morillo Cerdán, Ángel (ed.), Arqueología Militar Romana en Hispania, Madrid, CSIC; Polifemo, 2002.

Morillo Cerdán, Ángel (ed.), Arqueología militar romana en Hispania II: Producción y abastecimiento en el ámbito militar, León, Servicio de Publicaciones de la Universidad de León, 2006.

Morillo Cerdán, Ángel; Hanel, Norbert y Martín Hernández, Esperanza (eds.), Limes XX. Estudios sobre la frontera romana, Madrid, CSIC; Polifemo, 2009. 
Noguera, Jaume M.; Ble, Eduard y Valdés Matías, Pau, "Metal Detecting for Surveying Marching Camps? Some Thoughts Regarding Methodology in Light of the Lower Ebro Roman Camps Project's Results", en L. Vagalinski y N. Sharankov (eds.), Limes XXII. Proceedings of the 22nd International Congress of Roman Frontier Studies Ruse, Bulgaria, September 2012, Sofía, NAIM-BAS, 2015, págs. 853-860.

Noguera, Jaume M.; Principal, Jordi y Ñaco Del Hoyo, Toni, "La actividad militar y la problemática de su reflejo arqueológico: el caso del Noreste de la Citerior (218-45 a.C.)", en Cadiou. F. y M. Navarro Caballero (eds.), La guerre et ses traces. Conflits et sociétés en Hispanie à l'époque de la conquête romaine (IIIe-Ier s. a.C.), Bordeaux, Ausonius, 2014, págs. 31-56.

O'driscoll, James, "Landscape applications of photogrammetry using unmanned aerial vehicles", Journal of Archaeological Science: Reports, 22 (2018), págs. 32-44.

Ocharán Larrondo, José Antonio y Unzueta Portilla, Miguel, “Andagoste (Cuartango, Álava): Un nuevo escenario de las guerras de conquista en el norte de Hispania”, en Á. Morillo Cerdán (ed.), Arqueología Militar Romana en Hispania, Madrid, CSIC; Polifemo, 2002, págs. 311-325.

Orejas, Almudena; Sánchez-Palencia, Francisco Javier y Ron Tejedo, José Antonio, "Proyecto IVGA: conquista, dominación y explotación minera entre el conventus de los astures y el lucense", en P. León Gasalla (ed.), Excavaciones Arqueológicas en Asturias 2013-2016, Oviedo, Consejería de Educación y Cultura, Principado de Asturias - Ediciones Trabe, 2018, págs. 239-252.

Orejas, Almudena; Sánchez-Palencia, Francisco Javier; Beltrán, Alejandro; Ron, José Antonio; López, Luís Francisco; Currás, Brais X.; Romero, Damián; Zubiaurre, Elena; Pecharromán, Juan Luís y Arboledas, Luís, "Conquista, articulación del territorio y explotación de recursos en el límite entre el convento lucense y el de los ástures (Proyecto IVGA)", en J. Camino Mayor, E. Peralta Labrador, y J. F. Torres Martínez (eds.), Las Guerras Astur-Cántabras, Gijón, KRK Ediciones, 2015, págs. 247-260.

Orton, Clive, Sampling in Archaeology, Cambridge, Cambridge University Press, 2000.

Parcero Oubiña, César; Méndez, Fidel y Blanco-Rotea, Rebeca, El registro de la información en Intervenciones Arqueológicas, Santiago de Compostela, Laboratorio de Arqueoloxía e Formas Culturais (GIArPa), IIT, USC, 1999.

Peralta Labrador, Eduardo, "Los campamentos romanos de campaña (castra aestiva): evidencias científicas y carencias académicas", Nivel Cero. Revista del grupo arqueológico Attica, 10 (2002), págs. 49-87.

Peralta Labrador, Eduardo, "Equipamiento militar romano de la conquista de la antigua Cantabria”, Sautuola: Revista del Instituto de Prehistoria y Arqueología Sautuola, 13 (2007), págs. 493-511.

Peralta Labrador, Eduardo, "La penetración del ejército romano por el interfluvio Pas-Besaya", en J. Camino Mayor, E. Peralta Labrador, y J. F. Torres-Martínez (eds.), Las Guerras Ástur-Cántabras, Gijón, KRK Ediciones, 2015, págs. 131-148.

Peralta Labrador, Eduardo; Hierro Gárate, Jose Ángel y Gutiérrez Cuenca, Emilio, "Las monedas de los campamentos romanos de campaña de las guerras cántabras del asedio de la Loma, Castillejo y Alambre”, Lucentum, 30 (2011), págs. 151-172. 
Reddé, Michel; Brulet, Raymond; Fellmann, Rudolf; Haalebos, Jan Kees y Von Schnurbein, Sigmar, Les fortifications militaires, Bordeaux, Ausonius, 2006.

Reimer, Paula J.; Bard, Edouard; Bayliss, Alex; Beck, J. Warren; Blackwell, Paul G.; Bronk Ramsey, Christopher; Buck, Caitlin E.; Cheng, Hai; Edwards, R. Lawrence; Friedrich, Michael; Grootes, Pieter M.; Guilderson, Thomas P.; Haflidason, Haflidi; Hajdas, Irka; Hatté, Christine; Heaton, Timothy J.; Hoffmann, Dirk L.; Hogg, Alan G.; Hughen, Konrad A.; Kaiser, K. Felix; Kromer, Bernd; Manning, Sturt W.; Niu, Mu; Reimer, Ron W.; Richards, David A.; Scott, Marian; Southon, John R.; Staff, Richard A.; Turney, Christian S. M. y Van Der Plicht, Johannes, "IntCal13 and Marine13 Radiocarbon Age Calibration Curves 0-50,000 Years cal BP”, Radiocarbon, 55.4 (2013), págs. 1869-1687.

Remondino, Fabio y Campana, Stefano, 3D Modeling in Archaeology and Cultural Heritage: Theory and Best Practices, Oxford, Archaeopress, 2014.

Rodríguez Colmenero, Antonio, "Lucus Augusti (Lugo). Introducción histórica y arqueológica", en M. P. García-Bellido (ed.), Los campamentos romanos en Hispania (27 a.C.-192 d.C): el abastecimiento de moneda, Vol. I, Madrid, CSIC, 2006, págs 29-60.

Ruíz Zapatero, Gonzalo, "La excavación arqueológica”, en M. García-Díez y L. Zapata Peña (eds.), Métodos y Técnicas de análisis y estudio en arqueología prehistórica. De lo técnico a la reconstrucción de los grupos humanos, Bilbao, UPV, 2013, págs. 39-72.

Taylor, R. Ervin y Bar-Yosef, Ofer, Radiocarbon Dating: An Archaeological Perspective, London, Routledge, 2014.

Vallori Márquez, Bartomeu; Bellón Ruíz, Juan Pedro y Rueda Galán, Carmen, Accampamenti, guarnigioni e assedi durante la Seconda Guerra Punica e la conquista romana (secoli III-I aC): prospettive archeologiche, Roma, Edizioni Quasar di Severino Tognon, 2019. Verhoeven, G.; Doneus, M.; Briese, Ch.; Vermeulen, F. "Mapping by matching: a computer vision-based approach to fast and accurate georeferencing of archaeological aerial photographs”, Journal of Archaeological Science, 39 (2012), págs. 2060-2070. 